\title{
LGR4 and LGR5 Regulate Hair Cell Differentiation in the Sensory Epithelium of the Developing Mouse Cochlea
}

OPEN ACCESS

Edited by:

Hansen Wang,

University of Toronto, Canada

Reviewed by:

Andy Groves,

Baylor College of Medicine, USA

Albert Edge,

Harvard Medical School, USA Angelika Doetzlhofer,

Johns Hopkins University, USA

*Correspondence: Magdalena Żak ent-research@umcutrecht.nl m.zak@ucl.ac.uk

Received: 02 March 2016 Accepted: 19 July 2016 Published: 05 August 2016

Citation: Żak M, van Oort T, Hendriksen FG, Garcia M-I, Vassart G and Grolman W (2016) LGR4 and LGR5 Regulate Hair Cell Differentiation in the Sensory Epithelium of the

Developing Mouse Cochlea.

Front. Cell. Neurosci. 10:186. doi: 10.3389/fncel.2016.00186

\begin{abstract}
Magdalena Żak ${ }^{1 *}$, Thijs van Oort ${ }^{1}$, Ferry G. Hendriksen ${ }^{1}$, Marie-Isabelle Garcia ${ }^{2}$, Gilbert Vassart ${ }^{2}$ and Wilko Grolman ${ }^{1}$

1 Department of Otorhinolaryngology and Head and Neck Surgery, Brain Center Rudolf Magnus, University Medical Center Utrecht, Utrecht, Netherlands, ${ }^{2}$ Institut de Recherche Interdisciplinaire en Biologie Humaine et Moléculaire, Faculty of Medicine, Université Libre de Bruxelles, Brussels, Belgium
\end{abstract}

In the developing cochlea, $\mathrm{Wnt} / \beta$-catenin signaling positively regulates the proliferation of precursors and promotes the formation of hair cells by up-regulating Atoh 1 expression. Not much, however, is known about the regulation of Wnt/ $\beta$-catenin activity in the cochlea. In multiple tissues, the activity of Wnt/ $\beta$-catenin signaling is modulated by an interaction between LGR receptors and their ligands from the R-spondin family. The deficiency in Lgr4 and Lgr5 genes leads to developmental malformations and lethality. Using the Lgr5 knock-in mouse line we show that loss of LGR5 function increases Wnt/ $\beta$-catenin activity in the embryonic cochlea, resulting in a mild overproduction of inner and outer hair cells $(\mathrm{OHC})$. Supernumerary hair cells are likely formed due to an up-regulation of the "pro-hair cell" transcription factors Atoh1, Nh/h1, and Pou4f3. Using a hypomorphic Lgr4 mouse model we showed a mild overproduction of OHCs in the heterozygous and homozygous Lgr4 mice. The loss of LGR4 function prolonged the proliferation in the mid-basal turn of E13 cochleae, causing an increase in the number of SOX2-positive precursor cells within the pro-sensory domain. The premature differentiation of hair cells progressed in a medial to lateral gradient in Lgr4 deficient embryos. No significant up-regulation of Atoh1 was observed following Lgr4 deletion. Altogether, our findings suggest that LGR4 and LGR5 play an important role in the regulation of hair cell differentiation in the embryonic cochlea.

Keywords: cochlea, development, hair cells, Wnt signaling, LGR4, LGR5

\section{INTRODUCTION}

Hearing is the process by which mechanical sound stimuli are transduced into electrical signals within the auditory nerve and transmitted to the cortex. The primary transducers of sound are the mechanosensory hair cells, residing within the sensory epithelia of the hearing organ, the cochlea.

The sensory epithelium is comprised of sensory hair cells and their surrounding auxiliary supporting cells. Both cell types originate from a progenitor pool of 'pro-sensory' cells all of which express the transcription factor SOX2, the Notch ligand Jagged1, and the cell cycle inhibitor p27 ${ }^{K I P 1}$ (Adam et al., 1998; Chen and Segil, 1999; Morrison et al., 1999; Kiernan et al., 2005; Brooker et al., 2006). Following terminal mitosis, a subset of pro-sensory cells up-regulate ATOH1, 
a bHLH transcription factor, and differentiates into hair cells (Bermingham et al., 1999; Zheng and Gao, 2000; Woods et al., 2004; Cotanche and Kaiser, 2010). Hair cells then instruct their neighbor cells to down-regulate ATOH1 and form the supporting cells (Lanford et al., 1999; Zine et al., 2001; Jeon et al., 2011).

Hair cells are very vulnerable and can be damaged by various factors, such as noise, ototoxic medication, and aging (Bodmer, 2008). An adult mammalian cochlea lacks regenerative potential and therefore hair cell loss is irreversible and leads to hearing loss. Recent studies, however, showed that a neonatal mouse cochlea possesses some regenerative capacities (revised in Atkinson et al., 2015).

Previous work suggests that some supporting cells possess regenerative capacity, mediated in part by the $\mathrm{Wnt} / \beta$-catenin signaling pathway (reviewed in Atkinson et al., 2015; Jansson et al., 2015; Zak et al., 2015). The Wnt/ $\beta$-catenin signaling pathway is a highly conserved signaling cascade controlling proliferation and hair cell formation in the developing inner ear (reviewed in Jansson et al., 2015; Zak et al., 2015). Wnt/ $\beta$-catenin signaling induces hair cell formation by up-regulating the expression of Atoh1, the main "pro-hair cell gene" (Shi et al., 2010 , 2014). Stimulating Wnt/ $\beta$-catenin signaling pathway in the supporting cells induces their proliferation and differentiation into hair cells in vivo and in vitro (Chai et al., 2012; Shi et al., 2012, 2013; Jan et al., 2013). The supporting cells that show this regenerative capacities express LGR5, a stem cell and progenitor cell marker present during embryonic development and in self-renewing tissues (Barker et al., 2007, 2010; Jaks et al., 2008; Garcia et al., 2009; Chai et al., 2012; Chen et al., 2014, 2015; Jacques et al., 2012; Shi et al., 2012, 2013; Plaks et al., 2013; Takeda et al., 2013; Yee et al., 2013; Bramhall et al., 2014; Kawasaki et al., 2014; Miller et al., 2014; Ng et al., 2014; Ren et al., 2014; Sukhdeo et al., 2014; Song et al., 2015).

LGR5, also known as GPR49, is a member of the leucinerich repeat-containing G-protein coupled receptors (LGRs) family, which is known for binding to their ligands from the $\mathrm{R}$-spondin family to potentiate the activity of $\mathrm{Wnt} / \beta$-catenin signaling pathway in vitro (Glinka et al., 2011; Ruffner et al., 2012; Carmon et al., 2014). In the fetal intestines, the lack of Lgr5 expression up-regulates Wnt/ $\beta$-catenin activity leading to precocious Paneth cell differentiation without detectable effects on the differentiation of other cell lineages or proliferation (Garcia et al., 2009). In the cochlea, the spatiotemporal expression pattern of LGR5 expression has been investigated (Chai et al., 2011; Shi et al., 2012), but the effects of Lgr5 deficiency have not yet fully been addressed.

In multiple tissues, LGR5 is expressed in cells that are also positive for LGR4, an another member of the LGR family (Snippert et al., 2010; de Lau et al., 2011; Mustata et al., 2011; Kinzel et al., 2014; Ren et al., 2014). LGR4, also known as GPR48, is involved in the regulation of $\mathrm{Wnt} / \beta$-catenin activity by playing a permissive role in the $\mathrm{Wnt} / \beta$-catenin signaling pathway (Mustata et al., 2011). The lack of Lgr4 expression decreases $\mathrm{Wnt} / \beta$-catenin activity leading to hypoplasia and developmental defects in many tissues (Mustata et al., 2011; Sone et al., 2013;
Wang et al., 2013; Kinzel et al., 2014). The expression and role of LGR4 in the developing cochlea has not yet been investigated.

In the present study, we investigated how the loss of LGR4 and LGR5 function affects Wnt/ $\beta$-catenin activity in the developing mouse cochlea and whether the lack of Lgr4 and Lgr5 expression influences the proliferation and hair cell differentiation in the embryonic cochlea.

\section{MATERIALS AND METHODS}

\section{Animals}

Lgr4-LacZ mice containing the LacZ knock-in allele at the Lgr4 locus were on a CD1 background (Leighton et al., 2001; Mendive et al., 2006; Mustata et al., 2011). We used the hypomorphic Lgr4-LacZ mutant mice because they display a milder phenotype than the null mutant mice, which show growth retardation associated with embryonic and neonatal lethality (Kato et al., 2006). Hypomorphic heterozygous Lgr4-LacZ mice are healthy and fertile, while hypomorphic homozygous Lgr4-LacZ mice survive 4 weeks after birth (Mendive et al., 2006). Inserting the LacZ reporter gene into the Lgr4 locus allows for easy examination of the spatial pattern of gene expression in tissue.

Lgr5-eGFP mice (Barker et al., 2007) containing the EGFPIres-CreERT2 cassette knocked-in at the transcriptional start site of Lgr5 were purchased from the Jackson Laboratory (Stock 008875) (Bar Harbor, Maine, ME, USA). Heterozygous Lgr5eGFP mice are healthy and fertile, while homozygous Lgr5-eGFP mice die perinatally. Inserting EGFP-Ires-CreERT2 cassette into the first exon of the gene enables colored labeling of cells that normally express Lgr5. Lgr5-eGFP mouse lines was on a C57BL/6 background.

C57BL/6JOlaHsd mice were obtained from Harlan Laboratories, Horst, The Netherlands.

For time breeding, females were examined daily for a vaginal plug. The day the plug was found was recognized as embryonic day 0.5 (E0.5), while the date of birth was recognized as postnatal day 0 (P0).

All animals had free access to both food and water and were kept under standard laboratory conditions. This study was carried out in accordance with the recommendation of the Animal Care and Use Committee of Utrecht University and the Local Ethical Committee of Université Libre de Bruxelles. All experimental procedures were approved by the Animal Care and Use Committee of Utrecht University (DEC 2013.I.04.048, DEC 2013.I.05.052, and DEC 2013.I.10.076) and by the Local Ethical Committee of Université Libre de Bruxelles (Ethical Protocol No. $534 \mathrm{~N})$.

\section{Genotyping}

Transgenic mice were genotyped using genomic DNA isolated from pieces of ears and tails. Genomic DNA was extracted using DNeasy Blood and Tissue kit from Qiagen according to the manufacturer's protocol. We used the following primer sets: Lgr4 UpA: 5' -CCA GTC ACC ACT CTT ACA CAA TGG CTA AC-3', Lgr4 DownB: 5'-ATT CCC GTA GGA GAT AGC GTC CTA G-3', Lgr4 DownC: 5'-GGT CTT TGA GCA CCA GAG GAC-3', Lgr5 
forward 5'-CTG CTC TCT GCT CCC AGT CT-3', Lgr 5 wild type reverse $5^{\prime}$-ATA CCC CAT CCC TTT TGA GC-3', Lgr5 mutant reverse $5^{\prime}$-GAA CTT CAG GGT CAG CTT GC-3'.

\section{Cryosectioning and Whole Mount Sample Preparation}

Heads from E14.5-E17, half sculls from P0-P1, and cochleae from P7-P42 mice were isolated in RNAlater and fixed in $2 \%$ paraformaldehyde (Sigma-Aldrich) in phosphate-buffered saline (PBS, pH 7.4) at room temperature for $1.5 \mathrm{~h}$. Cochleae dissected from P7 and older mice were decalcified in $0.5 \mathrm{mM}$ EDTA (Sigma-Aldrich) in PBS at $4^{\circ} \mathrm{C}$ for 2-4 days.

For cryosectioning, the cochleae were dehydrated by successively incubating them in 5, 10, and 25\% sucrose (SigmaAldrich) in PBS at $4^{\circ} \mathrm{C}$ for $2 \mathrm{~h}$. Next, the tissues were embedded in OCT compound (Sakura Finetek Europe B.V., Alphen aan Den Rijn, The Netherlands), cut into serial frozen sections of $10 \mu \mathrm{m}$ thickness using Leica CM3050 cryostat and mounted on SuperFrost*/plus microscope slides.

For whole mount samples, the otic capsule, the lateral wall, Reissner's membrane, tectorial membrane and modiolus were removed using fine forceps. Next, the organ of Corti was dissected and micro-dissected into individual turns.

\section{Immunohistochemistry}

Immunohistochemistry was performed on cryosections and cochlear whole mounts. The tissues were immersed in blocking solution consisting of $1 \%$ bovine serum albumin (BSA) and $0.1 \%$ triton X-100 (both from Sigma-Aldrich) in PBS for $30 \mathrm{~min}$ at room temperature. Next, specimens were incubated with primary antibodies at $4{ }^{\circ} \mathrm{C}$ overnight. On the next day, tissues were rinsed with PBS and incubated with secondary antibodies at room temperature for $1 \mathrm{~h}$. Both primary and secondary antibodies were diluted in $0.5 \%$ BSA in PBS. Afterward, tissues were again rinsed with PBS and mounted in Vectashield Antifade Mounting Medium with or without DAPI (Vector laboratories).

The following primary antibodies were used: anti-myosin7a (1:700; rabbit, Proteus Bioscience, 25-6790), anti-myosin7a (1:200; mouse, Developmental Studies Hybridoma Bank, 1381-c), anti-SOX2 (1:200; goat, Santa Cruz Biotechnology, s17320), anti-SOX2 (1:50, mouse, Millipore, MAB4343), antiSOX2 (1:250, BD Pharmingen, 561469) anti-acetylated tubulin (ACTBA) (1:50; mouse, Sigma-Aldrich, T7451), anti-prestin (1:700; goat, Santa Cruz Biotechnology, N-20, sc-22692), antiLGR4 (1:200; rabbit, Sigma-Aldrich, HPA030267, test of the antibody specificity shown in Supplementary Figure S1), antijagged1 (JAG1) (1:50; goat, Santa Cruz Biotechnology, C-20, sc-6011), anti-cyclinD1 (CCND1) (1:100; rabbit, Thermo Fisher Scientific, SP4, MA5-14512), anti- $\beta$-tubulin class III (TUJ1, 1:200; mouse, Covance, MMS-435P), anti-p75 NGF receptor (1:400; rabbit, Sigma-Aldrich, N3908), anti-MYO6 (1:300, Abcam, ab11096). Secondary antibodies were purchased from Molecular Probes Life Technologies. The following secondary antibodies were used: Alexa Fluor 488 donkey anti-rabbit (A21206), Alexa Fluor 488 donkey anti-mouse (A21202), Alexa Flour 594 donkey anti-rabbit (A21207), Alexa Flour 594 donkey anti-mouse
(A21203), Alexa Flour 594 donkey anti-goat (A11058), Alexa Flour 405 goat anti-rabbit (A31556), Alexa Flour 405 goat antimouse (A31553).

For F-actin staining, after completing incubation with the secondary antibodies, tissues were rinsed in PBS and incubated with rhodamine phalloidin $(1 \mu \mathrm{g} / \mathrm{ml}$; Sigma-Aldrich, P1951) at room temperature for $1 \mathrm{~h}$. Afterward, tissues were again rinsed with PBS and mounted in Vectashield Antifade Mounting Medium with or without DAPI (Vector laboratories).

Stained tissues were analyzed using a Zeiss LSM700 Scanning Confocal Microscope. Pictures were processed using Zen software (Carl Zeiss) and Photoshop (Adobe Creative Suite 5).

\section{$\beta$-Galactosidase Staining}

Staining was performed on cryosections. Tissues were washed with $2 \mathrm{mM} \mathrm{MgCl}_{2}$ in PBS twice for 5 min each at room temperature and incubated in X-gal (4\%) mixed with X-gal mixer $(1: 40, \mathrm{v} / \mathrm{v})$ at $37^{\circ} \mathrm{C}$ for $2-4 \mathrm{~h}$. X-gal mixer comprises $5 \mathrm{mM}$ $\mathrm{K}_{3} \mathrm{Fe}(\mathrm{CN})_{6}, 5 \mathrm{mM} \mathrm{K}_{4} \mathrm{Fe}(\mathrm{CN})_{3} \mathrm{H}_{2} \mathrm{O}, 0.01 \%$ sodium deoxycholate, $0.2 \%$ Nonidet NP-40, $2 \mathrm{mM} \mathrm{MgCl}_{2}$ (all from Sigma-Aldrich) in PBS. Next, tissues were rinsed with PBS and mounted in Mowiol (Sigma-Aldrich). Cell nuclei were stained with Nuclear Fast Red (Vector laboratories) according to the manufacturer's protocol. Using this protocol, we stained cochleae from 3 Lgr4LacZ knock-out and heterozygous mice. Control experiments found no non-specific staining in cochleae harvested from 3 wild type littermates.

\section{EdU Labeling}

EdU (Invitrogen) was prepared in water at a concentration of $1 \mathrm{mg} / \mathrm{ml}$. Pregnant females were injected intraperitoneally with $5 \mu \mathrm{g}$ EdU per gram of body weight on day 13.5 post coitum. Females were injected three times with $2 \mathrm{~h}$ intervals and sacrificed $24 \mathrm{~h}$ after first injection. Next, heads of the embryos were collected and processed for cryosections. Sections underwent heat-induced antigen retrieval in sodium citrate buffer $(10 \mathrm{mM}$, $\mathrm{pH}=6$ ) containing $0.05 \%$ Tween 20 . Edu staining was performed using the Click-iT EdU Alexa Fluor 594 Imaging kit (Molecular Probes, Invitrogen) according to the manufacturer's protocol.

\section{Plastic-Embedded Surface Preparations}

Cochleae were isolated from Lgr4-LacZ mice at the age of P21-P24. We used three animals per genotype. Cochleae were perfused with trialdehyde [ $3 \%$ glutaraldehyde, $2 \%$ formaldehyde, $2.5 \%$ DMSO (all from Merck), 1\% acrolein (Fluka), and 0.08M sodium cacodylate buffer (Sigma-Aldrich), $\mathrm{pH}$ 7.4] and then immersed in the same trialdehyde fixative for $3 \mathrm{~h}$ at room temperature. Next, cochleae were rinsed in $0.1 \mathrm{M}$ sodium cacodylate buffer and decalcified in 10\% EDTA (Sigma-Aldrich) $\mathrm{pH} 7.4$ for $4-5$ days at room temperature. Afterward, tissues were post-fixated with $1 \%$ osmium tetroxide (Sigma-Aldrich) and $1 \%$ potassium hexacyanoruthenate (II) hydrate (Alfa Aesar) for $2 \mathrm{~h}$ at $4^{\circ} \mathrm{C}$ and dehydrated with ethanol gradient. After being washed with 1,2-propylene oxide (Merck), cochleae were embedded in Spurr's low-viscosity resin as previously described (Spurr, 1969).

Plastic-embedded cochleae were cut into two halves along the mid-modiolar plane, the half-turns were dissected and mounted 
onto glass microscope slides. Specimens were analyzed using a Zeiss Axiophot microscope equipped with DIC optics.

\section{Scanning Electron Microscopy}

Cochleae were isolated from Lgr4-LacZ mice at the age of P21-P24. We used three animals per genotype. Cochleae were fixed with $2 \%$ glutaraldehyde in $0.1 \mathrm{M}$ sodium cacodylate buffer (Sigma-Aldrich) pH 7.4 at $4^{\circ} \mathrm{C}$ overnight. On the next day, individual half-turns were micro-dissected and postfixed using OTO method. Briefly, after being incubated with $1 \%$ osmium tetroxide (Sigma-Aldrich) for $30 \mathrm{~min}$ at room temperature, tissues were rinsed in water and incubated with $1 \%$ thiocarbohydrazide (Merck) for $30 \mathrm{~min}$ at room temperature. Next, tissues were again washed in water and incubated with $1 \%$ osmium tetroxide. Afterward, tissues were dehydrated with ethanol gradient and hexamethyldisilazane (Sigma-Aldrich). Dried specimens were placed on aluminum stubs covered with adhesive carbon disks (Agar Scientific) and analyzed using a Phenom Pro Scanning Electron Microscope.

\section{Cell Counting}

Sox2-positive cells were counted in cryosections from E14.5 cochleae isolated from Lgr4-LacZ and Lgr5-eGFP mice. We counted Sox2-positive cells in the apical and mid-basal turns from three different animals per genotype.

We counted hair cells using either cochlear whole mounts obtained from P0 Lgr5-eGFP mice and stained with F-actin, or plastic-embedded surface preparations obtained from P21-P24 Lgr4-LacZ mice.

For cell counts in Lgr5-eGFP mice, we captured multiple images that covered the entire surface area of the specimens and then using Photoshop we constructed a composite picture encompassing the whole area of each whole mounted sensory epithelium. Next, using ImageJ we measured the entire length of each specimen and counted hair cells across a $450 \mu \mathrm{m}$ region at 25,50 , and $75 \%$ positions along the length of the cochlear duct. Cochleae from 3 animals per genotype were analyzed.

For cell counts in Lgr4-LacZ mice, microscopic pictures were taken with a video camera and projected on an LCD-monitor to enable counting. The width of the screen corresponded to $150 \mu \mathrm{m}$ of the specimen and the height corresponded to $110 \mu \mathrm{m}$. For each cochlea, the total length of the cochlear duct was calculated by adding the length of all the analyzed monitor projections. Next, the total number of hair cells across a $450 \mu \mathrm{m}$ region at 25,50 , and $75 \%$ positions along the length of the cochlear duct was calculated. Cochleae from 3 animals per genotype were analyzed.

\section{Quantitative PCR}

Total RNA was isolated from cochleae obtained from 3 to 6 animals using RNeasy Mini Kit and QIAshredder columns (Qiagen) according to the manufacturer's instructions. Next, genomic DNA was removed using DNase I (Roche) and cDNA was synthesized using iSript cDNA Synthesis kit (Bio-Rad). qPCR reactions were performed with Quantifast Syber Green (Qiagen) according to the Qiagen real-time cycler conditions and using the iCycler MyiQ machine (Bio-Rad). Each PCR reaction was repeated in triplicate and the results were analyzed using iQ5 software (Bio-Rad). The relative quantification of gene expression was analyzed using the $\Delta \Delta \mathrm{Ct}$ method with Gapdh as the endogenous reference (Pfaffl, 2001).

The following primers were used: Gapdh forward 5'-AAC GAC CCC TTC ATT GAC-3', Gapdh reverse 5'-TCC ACG ACA TAC TCA GCA C-3', Lgr4 forward 5' -CGA CTT CGC ATT CAC CAA CCT TTC- $3^{\prime}$, Lgr4 reverse $5^{\prime}$-CAA GTC CAG GGT TTC CAG GTT ATC-3' ${ }^{\prime}$, Lgr 5 forward 5'-CGT TCG TAG GCA ACC CTT CTC TTA-3', Lgr5 reverse 5'-CGA GGC ACC ATT CAA AGT CAG TGT-3', Lgr6 forward $5^{\prime}$-CGC TAT CTT TGA ATG GTG CCA CTG A- $3^{\prime}$, Lgr6 reverse $5^{\prime}$-TTA TGA GAC AGC TCC AGG ATT CGG-3', Axin2 forward 5' -TGA CTC TCC TTC CAG ATC CCA-3', Axin2 reverse $5^{\prime}$-TGC CCA CAC TAG GCT GAC A- $3^{\prime}$, Pou $4 f 3$ forward $5^{\prime}$-GAA CCC AAA TTC TCC AGC CTA CAC- $3^{\prime}$, Pou $4 f 3$ reverse $5^{\prime}$-GTC GGG CTT GAA CGG ATG ATT CTT-3', Nhlh1 forward 5'-TGC AGA CAG ATG ACC CTT GA$3^{\prime}$, Nhlh 1 reverse 5'-ACT GAG CTC TGG GAA GCA GTT A-3', Cyclin D1 forward 5'-GTT CAT TTC CAA CCC ACC CTC - $3^{\prime}$, Cyclin D1 reverse 5'-AGA AAG TGC GTT GTG CGG TAG3', Atoh1 forward 5'-TTT CCC CAA CTG CTT GAG AC-3', Atoh1 reverse 5'-TGC ATT GGC AGT TGA GTT TC-3', Lgr5 exon1 forward 5'-ACG ATT CTC TGC GCG GTC-3', Lgr5 exon1 reverse 5'- GGG CTG ATG CAG AAC CGA-3'.

\section{Statistical Analysis}

Statistics were conducted using Microsoft Excel (Microsoft) and SPSS 21 (IBM). The One-way ANOVA test or unpaired Student's $t$-test was utilized with $p<0.05$ considered statistically significant. The Tukey's HSD or Games Howell post hoc test was applied. All data are presented as a group mean with standard deviation. Graphs were prepared using Adobe Illustrator (Adobe Creative Suite 5) and asterisks are used to show significance $\left({ }^{*} \leq 0.05 ;^{* *} \leq 0.01 ;^{* * *} \leq 0.001\right)$ in Figures 1, 2, 6, 8, and 10.

\section{RESULTS}

\section{Homozygous Lgr5-eGFP Mice Generated Supernumerary Hair Cells and Supporting Cells}

In the developing cochlea, LGR5 is expressed in the pro-sensory cells that are positive for $\mathrm{Wnt} / \beta$-catenin activity and give rise to both hair cells and the supporting cells (Chai et al., 2011; Jacques et al., 2012).

To determine if loss of Lgr5 affects hair cell differentiation, cochleae were isolated from newborn Lgr5-eGFP mice representing all three genotypes and stained with phalloidin to analyze the hair cell organization. In both heterozygous Lgr5-eGFP mice and their wild type littermates one row of inner hair cells (IHCs) and three rows of outer hair cells (OHCs) were evidenced (Figure 1A). Occasionally, misaligned IHCs were observed in heterozygous Lgr5-eGFP mice (Figure 1A). In contrast, homozygous Lgr5-eGFP mice showed pronounced misaligned hair cells and an overproduction of IHCs (Figure 1A).

This phenotype was analyzed along the whole cochlea. Hair cells were counted along the cochlear length at $25 \%$ of cochlear 

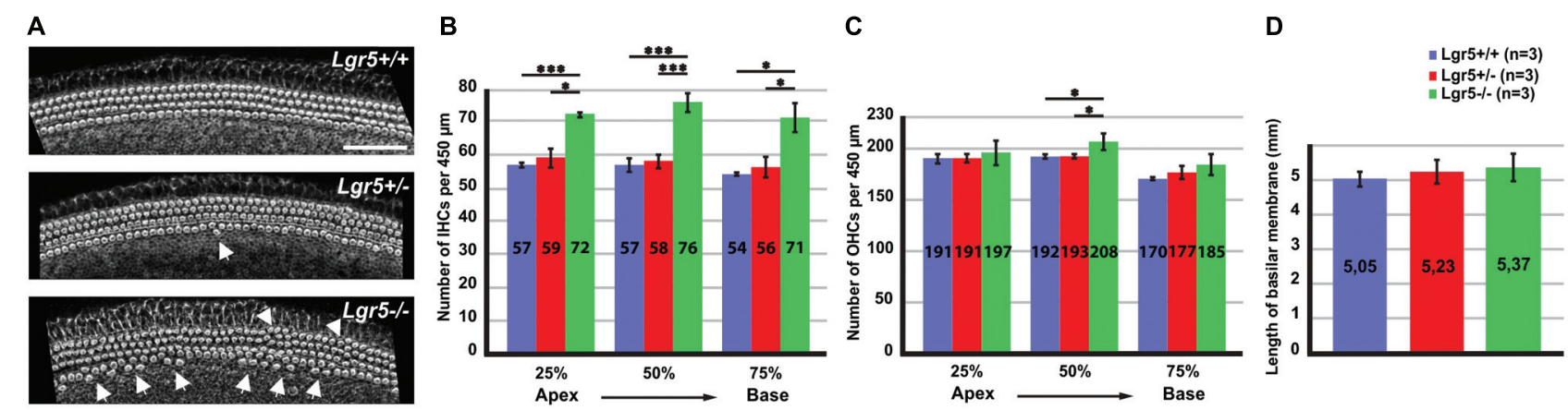

FIGURE 1 | Overproduction of hair cells in Lgr5-eGFP mice. (A) A reconstruction of Z-stack images of the cochlear mid-basal turns stained with phalloidin. Homozygous Lgr5-eGFP mice showed overproduction of IHCs (arrows) and OHCs (arrowheads). (B) The number of IHCs was significantly increased along the cochlear duct in the homozygous Lgr5-eGFP mice. (C) The number of OHCs was also significantly increased in the mid-basal turn of the cochleae isolated from homozygous Lgr5-eGFP mice. (D) Comparing the length of basilar membrane between the Lgr5 deficient mice and their wild type littermates.

length (apical turn), 50\% of cochlear length (mid-basal turn), and $75 \%$ of cochlear length (basal turn). The number of IHCs per $450 \mu \mathrm{m}$ significantly increased at all three analyzed positions in homozygous Lgr5-eGFP mice as compared to their wild type and heterozygous Lgr5-eGFP littermates (Figure 1B). Additionally, the number of OHCs in the mid-basal region also increased from $192 \pm 1.7(n=3)$ in wild type mice and $193 \pm 1.5(n=3, p \leq 0.05)$ in heterozygous Lgr5-eGFP mice to $208 \pm 8.1(n=3, p \leq 0.05)$ in homozygous Lgr5-eGFP mice, whereas the number of OHCs remained similar in the apical and basal turns in all genotypes (Figure 1C).

Then, we tested whether the supernumerary cells were formed due to abnormal cochlear convergence. If cochlear duct does not elongate properly, the sensory epithelium is shorter but the number of hair cells is unaffected. Since the hair cells do not have enough space along the cochlear duct, they form extra rows of hair cells (Montcouquiol et al., 2003; Wang et al., 2005; Qian et al., 2007). We compared the length of basilar membrane in Lgr5 deficient mice and their control littermates, but no significant differences could be observed (Figure 1D). Thus, these data excluded that the supernumerary hair cells had resulted from a malfunction in cochlear convergence in homozygous Lgr5-eGFP (Figure 1D).

To determine whether differentiation of supporting cells was altered by L $\operatorname{rr} 5$ deficiency, we isolated the sensory epithelia from newborn Lgr5-eGFP littermates and stained them with p75 (NGFR), a protein exclusively expressed in the supportive inner pillar cells (IPCs) (Gestwa et al., 1999; Mueller et al., 2002; Doetzlhofer et al., 2009; Jahan et al., 2015). In the apical and mid-basal and basal turns of cochleae isolated from wild type mice and their heterozygous littermates, p75 was detected in the IPCs localized between three rows of OHCs and the single

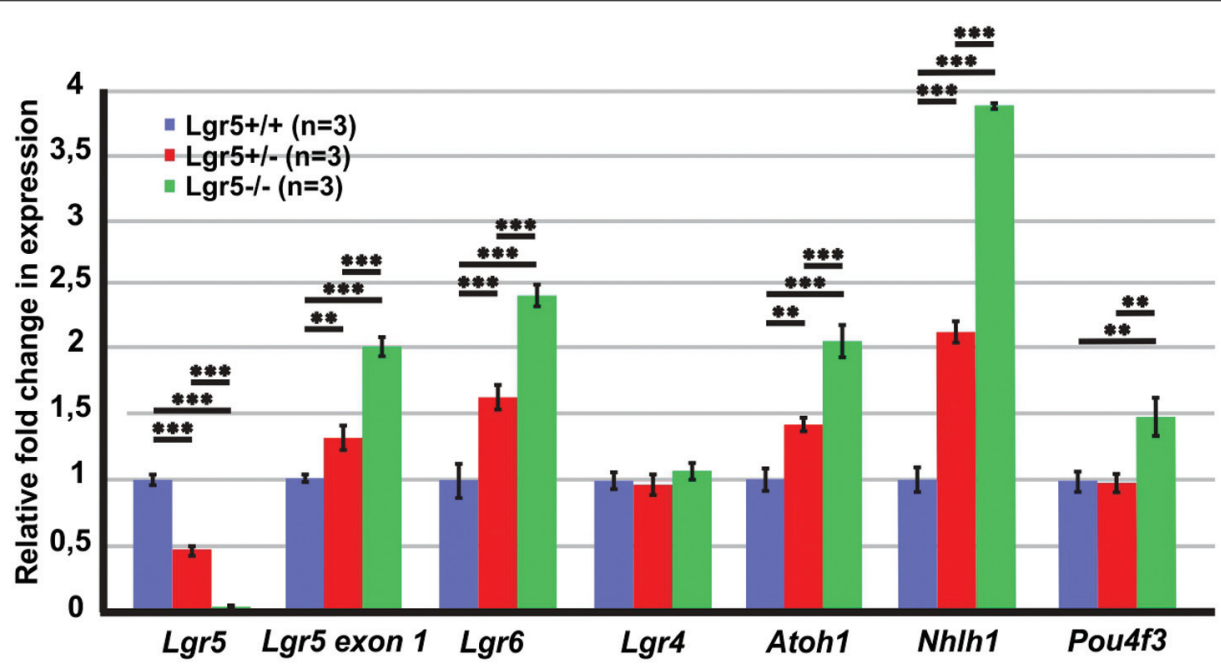

FIGURE 2 | qPCR results for the E13 cochleae of Lgr5-eGFP embryos. The expression of $L$ gr5 significantly decreased in the cochleae isolated from homozygous and heterozygous Lgr5-eGFP mice. The expression from Lgr5 exon1 and the expression of Lgr6, Atoh1, and Nhlh1 significantly increased in homozygous and heterozygous Lgr5-eGFP mice, while the expression of Pou4f3 increased only in the homozygous $L g r 5$-eGFP mice. The expression of Lgr4 was unaffected. 
row of IHCs (Supplementary Figures S2A,A'). Similar staining pattern was observed in the cochleae harvested from homozygous Lgr5-eGFP mice (Supplementary Figure S2A").

In the cochleae isolated from wild type mice and their heterozygous littermates, SOX2 was detected in a subset of supporting cells, including inner and outer pillar cells (IPCs and OPCs) and three rows of Deiters' cells (Supplementary Figures S2B,B'). At the mid-basal turn of cochleae harvested from homozygous Lgr5-eGFP mice, four Deiters' cells positive for SOX2 were localized beneath four OHCs (Supplementary Figure S2B"). These results imply that the supernumerary hair cells detected in the cochleae of homozygous Lgr5-eGFP mice were not formed at the expense of the supporting cells. Altogether, these data show that, at birth, Lgr5 deficiency results in the over-production of both hair cells and supporting Deiters' cells.

\section{Lgr5 Deficient Mice Showed Increased Wnt/ $\beta$-Catenin Activity Associated with Increased Expression of "Pro-hair Cell Genes"}

In the fetal intestines, Lgr5 deficiency up-regulates the Wnt/ $\beta$-catenin signaling pathway causing precocious differentiation of Paneth cells (Garcia et al., 2009). To determine if the supernumerary hair cells observed in homozygous Lgr5-eGFP mice could be similarly related to an abnormal $\mathrm{Wnt} / \beta$-catenin stimulation, we tested by $\mathrm{qPCR}$ the level of expression of several Wnt/ $\beta$-catenin target genes in E13 cochleae (Chai et al., 2011).

First of all, the expression of Lgr5 was tested using two different primer pairs. From the pair of primers spanning exons 8-10, we could confirm the genotypes with barely detectable expression of Lgr5 in homozygous Lgr5-eGFP embryos (Figure 2). In contrast, with the use of a primer pair detecting exon 1 expression, which is upstream of the inserted cassette in the analyzed Lgr5-eGFP mouse model, we observed that transcription from the $\operatorname{Lgr} 5$ promoter was increased by a fold change of $2.0 \pm 0.06(n=3, p \leq 0.001)$ in homozygous Lgr5-eGFP mice as compared to their wild type littermates (Figure 2).

The paralogue LGR6 receptor is also expressed in the prosensory domain and, in vitro, its expression is maintained by Wnt/ $\beta$-catenin activity (Zhang et al., 2015). It is also transiently expressed in IPCs around birth (Zhang et al., 2015). We found that Lgr6 expression was also increased by a fold change of $2.4 \pm 0.1(n=3, p \leq 0.001)$ in homozygous Lgr5-eGFP mice whereas that of the third member of the Lgr family, the paralogue Lgr4, a non-Wnt/ $\beta$-catenin target gene, was expressed at similar levels in the three genotypes (Figure 2).

We also tested expression of Atoh1, a reported Wnt/ $\beta$-catenin target gene that induces formation of hair cells in the sensory and non-sensory cochlear epithelium (Bermingham et al., 1999; Zheng and Gao, 2000; Woods et al., 2004; Shi et al., 2010, 2014; Mulvaney et al., 2015). In homozygous Lgr5-eGFP embryos, Atoh1 expression was significantly increased by a fold change of $2.1 \pm 0.1(n=3, p \leq 0.001)$ as compared to their wild type littermates (Figure 2). In addition, we tested the expression of two transcription factors Nhlh1 and Poutf that are necessary for formation and maintenance of hair cells (Xiang et al., 1997, 1998; Kruger et al., 2006). These factors are positively regulated by Atoh 1 in the developing mouse cerebellum, an ex vivo model of the developing mouse sensory epithelium, and in transfected mammalian cell lines (Klisch et al., 2011; Masuda et al., 2011; Ikeda et al., 2015). In the E13 homozygous Lgr5-eGFP cochleae, expression of Nhlh1 and Pou $f f 3$ were significantly increased by a fold change of $3.9 \pm 0.1(n=3, p \leq 0.001)$ and $1.5 \pm 0.1(n=3$, $p \leq 0.01)$ as compared to their wild type littermates, respectively (Figure 2). Together, these results suggested that the lack of Lgr5 expression leads to an up-regulation of $\mathrm{Wnt} / \beta$-catenin activity in the pro-sensory cells of the embryonic E13 cochlea, resulting in an induction of "pro-hair cell genes" and consequently to supernumerary hair cell differentiation.

\section{The Loss of Lgr5 Function Did Not Increase Proliferation}

Next, we tested if the increased total number of cells could be associated with an increased proliferation. We tested the expression of Cyclin D1 (Ccnd1), a gene required for cell cycle progression (Massague, 2004), but no significant changes could be detected (Figure 3). We also tested the expression of two cell cycle inhibitors, which are known to be expressed in the developing cochlea, p27Kip1 and p57Kip2 (Lowenheim et al., 1999; Lee et al., 2006; Liu and Zuo, 2008; Laine et al., 2010; Oesterle et al., 2011). The expression of p27Kip1 and p57Kip2 did not change in the cochleae of Lgr5 deficient embryos (Figure 3). These results suggested that the supernumerary cells detected in homozygous Lgr5-eGFP mice are most likely not due to increased proliferation.

To confirm this assumption, EdU labeling of proliferating cells was performed in vivo using Lgr5-eGFP mouse model. Pregnant females were injected three times with $2 \mathrm{~h}$ intervals at 13.5 days of gestation and sacrificed $24 \mathrm{~h}$ after first

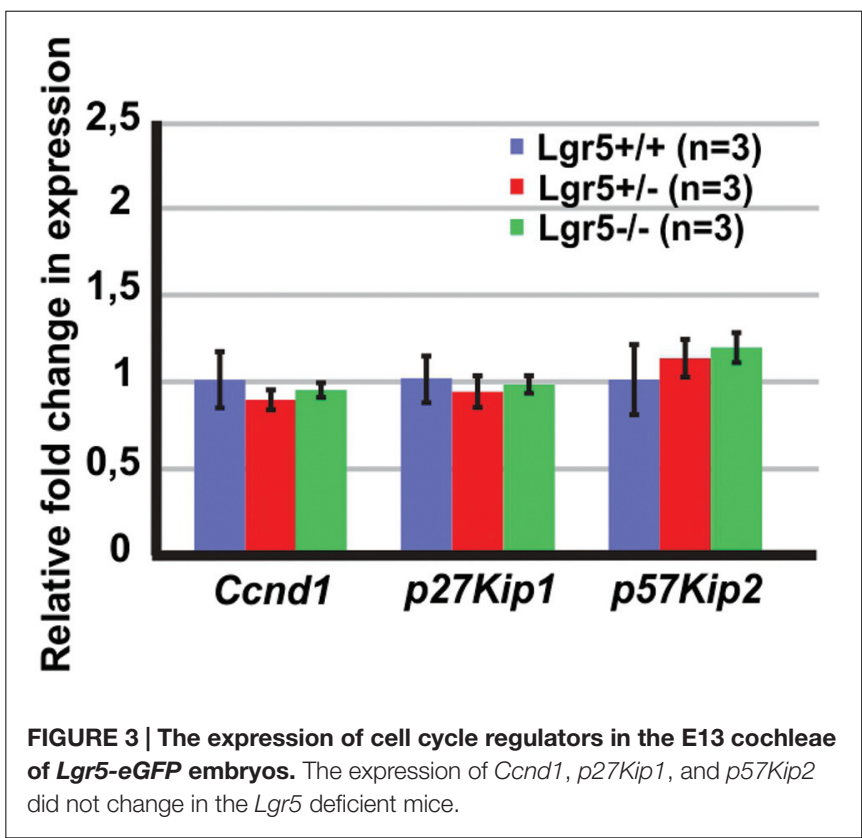


injection. In the E14.5 cochleae, EdU labeling was detected medial to pro-sensory domain in the apical turn and in mesenchyme surrounding the cochlear duct in wild type as well as heterozygous and homozygous Lgr5-eGFP mice (Figures 4A$\left.\mathbf{A}^{\prime \prime}\right)$. In the mid-basal turns, EdU-positive cells were observed only in mesenchyme outside the cochlear duct (Figures 4BB"). None of the pro-sensory cells was EdU-positive, which confirms that the loss of Lgr5 function did not increase proliferation.

\section{LGR4 Expression in the Developing Mouse Cochlea}

In many other tissues, LGR4 is co-expressed with LGR5 in Wnt/ $\beta$-catenin-responsive cells, in which the lack of Lgr4 expression decreases $\mathrm{Wnt} / \beta$-catenin activity (Snippert et al., 2010; de Lau et al., 2011; Mustata et al., 2011; Sone et al., 2013; Wang et al., 2013; Kinzel et al., 2014; Ren et al., 2014). We sought to investigate the spatiotemporal expression of LGR4 in the developing mouse cochlea to see if LGR4 is coexpressed with LGR5 in the same subset of cochlear cells. Our qPCR results obtained from E13 cochleae of LGR5-eGFP mice demonstrated that Lgr4 is also expressed in the developing mouse cochlea. We used a collection of samples comprising six additional time points, representing different developmental events during cochlear development: E12 (proliferation), E17 (hair cell differentiation), P0 (birth), P8 (before onset of hearing), P21 (after onset of hearing), and P42 (adult cochlea). Our results confirmed that Lgr4 and Lgr5 are co-expressed in the developing mouse cochlea (Supplementary Figure S3A).

Firstly, we examined LGR4 expression in the developing cochlea using immunohistochemistry. At embryonic day E14.5, strong LGR4 signals were detected in the cochlear duct in the apical and mid-basal turns (Figure 5A; Supplementary Figure S1). LGR4 signals were detected not only in the pro-sensory domain, where it overlapped with SOX2, but also in the non-sensory domains flanking the pro-sensory domain and in mesenchymal cells medial to the cochlear duct (Figure 5A; Supplementary Figure S1). Additionally, LGR4 positive signals were observed in spiral ganglion cells throughout cochlear development, evidenced by comparing the expression of LGR4 with TUJ1, a marker for neural cells (Figures 5A,C,F; Supplementary Figure S1). In the cochlea at embryonic day E17, LGR4 was broadly distributed in the sensory epithelium with particularly strong staining in the differentiating hair cells, which were positive for F-actin (Figure 5B). At postnatal day P1, LGR4 was detected in the organ of Corti and in the greater epithelial ridge (Figure 5C). As the cochlea maturated, LGR4 expression decreased in the hair cells and became restricted to the Deiters' cells. At P7, LGR4 was still strongly expressed in the hair cells, Deiters' cells, as well as IPCs and OPCs (Figure 5D). At P21, LGR4 staining was detected in the IHCs and Deiters' cells (Figures 5E,G). LGR4 expression was not detected in the OHCs because LGR4 staining did not overlap with prestin, a marker that specifically labels the OHCs. At P42, LGR4 was evident in Deiters' cells that were localized beneath the OHCs labeled with prestin (Figure 5H).

To confirm the results obtained by immunohistochemistry, we performed X-gal staining on cochlear sections obtained from Lgr4-LacZ mice at the age of P21. In line with immunohistochemistry staining, the expression of the reporter gene was detected in the IHCs, Deiters' cells, and spiral ganglion cells (Figures 5I,J).

To determine whether Lgr4 and Lgr5 are co-expressed in the developing mouse cochlea in the same cell subtypes, we applied immunohistochemistry on cochlear sections obtained from heterozygous Lgr5-eGFP mice. In the E17 cochlea of Lgr5eGFP mice, LGR5-eGFP was detected in the entire organ of Corti, including hair cells and various supporting cells (Supplementary Figure S3B). At this time point, LGR4 was strongly expressed in the differentiating hair cells, where it co-localized with LGR5eGFP and MYO7a (Supplementary Figure S3B). At P21, LGR5eGFP strongly stained the IHCs and the third row of Deiters' cells, but weaker LGR5-eGFP stains were also detected in the first two
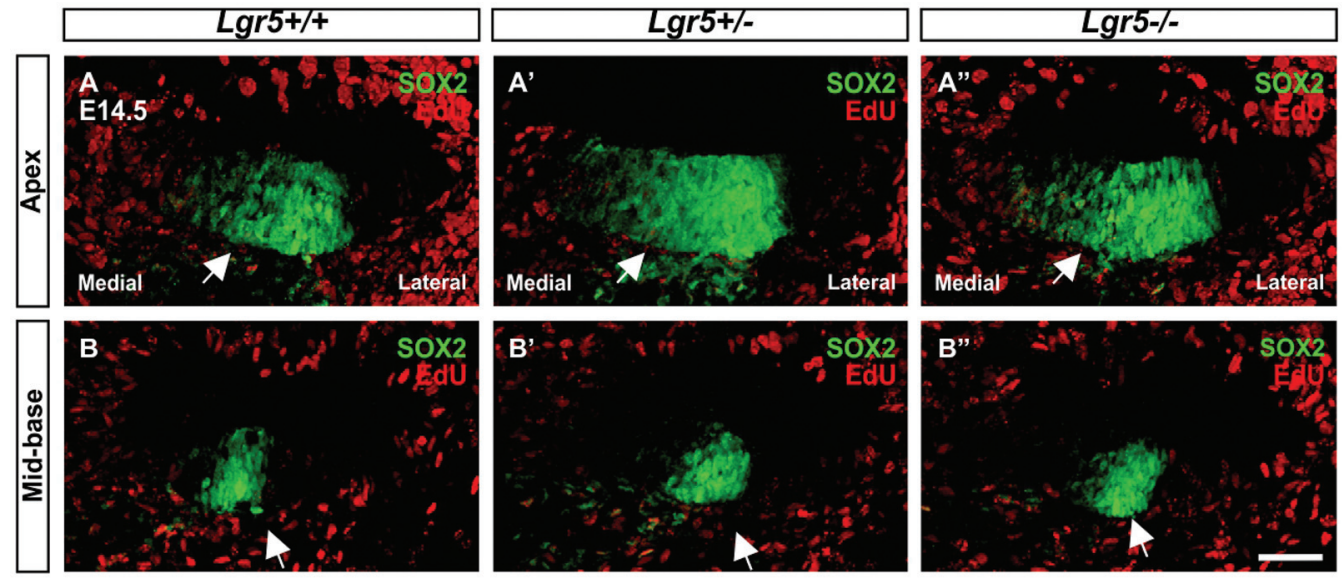

FIGURE 4 | Proliferation in the cochleae of E14.5 Lgr5-eGFP embryos. (A-B") SOX2-positive pro-sensory cells (green, arrow) did not incorporate EdU (red). Cell nuclei were counterstained with DAPI (blue), scale bars indicate $25 \mu \mathrm{m}$. 

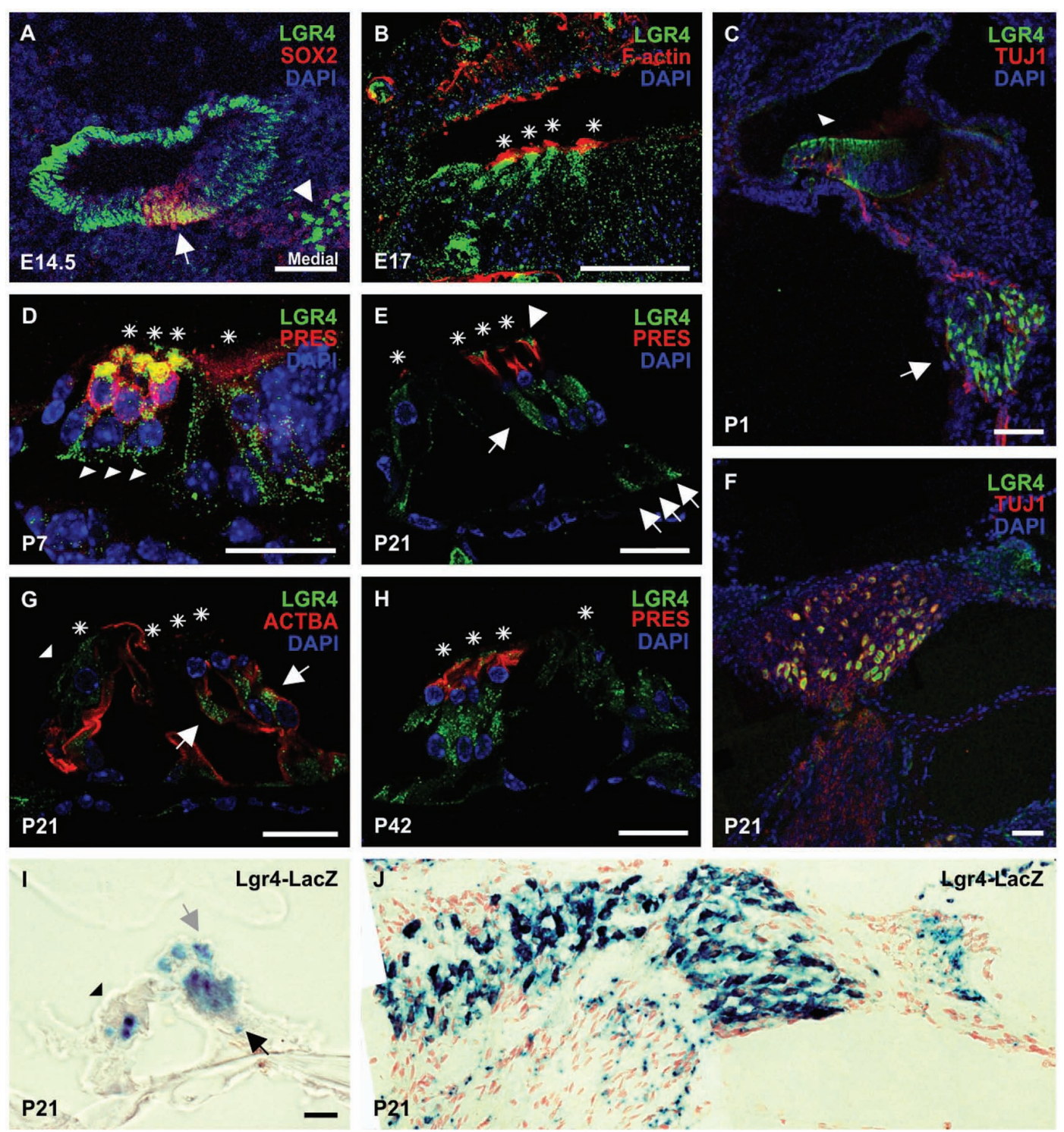

FIGURE 5 | The distribution of LGR4 in the developing mouse cochlea. (A) At E14.5, strong LGR4 staining was detected in the cochlear duct and spiral ganglion cells (white arrowhead). LGR4 was detected in the pro-sensory domain, where it overlapped with SOX2 (white arrow), and non-sensory domains lateral and medial to the pro-sensory domain. (B) At E17, LGR4 (green) was detected in IHCs and OHCs (asterisks) and their surrounding supporting cells. Hair cells were labeled with phalloidin (F-actin) (red). (C) At P1, LGR4 expression was observed in the sensory epithelium (arrowhead) and spiral ganglion cells (arrow), from which projected TUJ1-positive nerves (red). (D) At P7, LGR4 was observed in hair cells (asterisks) that co-expressed Prestin (PRES) and in the surrounding supporting cells: Deiters' cells (arrowheads) and IPCs and OPCs. (E-G) At P21, LGR4 was down-regulated in the OHCs and pillar cells, but was still expressed in the IHCs (arrowhead), Deiters' cells (arrows), which were also positive for acetylated tubulin (ACTBA), and phalangeal processes of Deiters' cells (arrowheads). LGR4 signals were also observed in the spiral ganglion cells. (H) At P42, LGR4 was detected in Deiters' cells and their phalangeal processes. Cell nuclei were counterstained with DAPI (blue), asterisks indicate hair cells, scale bars indicate $20 \mu \mathrm{m}$ in the picture (B,D,E,G,H) and $50 \mu \mathrm{m}$ in (A,C,F). (I,J) Cochlear cryosections from Lgr4-LacZ mice at the age of P21 were stained for $\beta$-galactosidase activity. Expression was seen in Deiters' cells (black arrow) and their phalangeal processes (gray arrow), IHCs (black arrowhead), and spiral ganglion cells.

rows of Deiters' cells (Supplementary Figure S3B). In the mature cochlea, LGR4 expression was also seen in the IHCs and all three Deiters' cells, where LGR4 was co-expressed with LGR5-eGFP (Supplementary Figure S3B). These results indicated that LGR4 co-localized with LGR5 in the same type of cells in the developing cochlea.

\section{Lgr4 Deficient Mice Generated Supernumerary OHCs and Deiters' Cells}

Next, we investigated if loss of LGR4 function could affect hair cell formation in the developing cochlea. Cochleae isolated from P21 Lgr4-LacZ littermates representing all three genotypes were analyzed by scanning electron microscopy (SEM). Wild type mice 
showed a clear pattern of three rows of OHCs and a single row of IHCs in the cochlea (Figure 6A). In contrast to their wild type littermates, heterozygous and homozygous Lgr4-LacZ mice showed supernumerary OHCs, usually organized in short patches forming a fourth row of OHCs (Figure 6A). The number of OHCs per $450 \mu \mathrm{m}$ increased from $190 \pm 0.5(n=3)$ in wild type mice to $218 \pm 1.1(n=3)$ in heterozygous Lgr4-LacZ mice and $215 \pm 1(n=3)$ in homozygous Lgr4-LacZ mice $(p \leq 0.001)$ (Figure 6C). Such phenotype was exclusively observed in the mid-basal region (Figure 6C). Moreover, in contrast to Lgr5 deficient mice, the number of IHCs was similar in all Lgr4-LacZ genotypes (Figure 6B).

To see whether the supernumerary supporting cells were also produced in excess in the Lgr4 deficient mice, whole mount preparations from P21 cochleae representing wild type and heterozygous Lgr4-LacZ mice were analyzed using Myosin7a (MYO7a) as a marker for hair cells, and phalloidin and acetylated tubulin (ACTBA) as markers for Deiters' cells and pillar cells. In contrast to their wild type littermates (Supplementary Figure S4A), four OHCs positive for MYO7a were localized above four Deiters' cells labeled with phalloidin and ACTBA in heterozygous Lgr4-LacZ mice, (Supplementary Figure S4B). This result implies that extra supporting cells were produced in addition to the supernumerary OHCs in the cochleae of Lgr4 deficient mice.

Since the length of basilar membrane in the Lgr4 deficient mice and their wild type littermates was not significantly different, we concluded that the fourth rows of OHCs and Deiters' cells were not formed due to abnormal cochlear convergence (Figure 6D). These data would imply that the increased number of OHCs in the Lgr4 deficient mice must have resulted from an increase in the total number of hair cells in the cochlea.

\section{Lgr4 Deficient Mice Showed Premature Hair Cell Differentiation in a Medial-to-Lateral Gradient}

To determine if extra OHCs in Lgr4 deficient mice was associated with premature hair cell differentiation, cochleae from E14.5
Lgr4-LacZ embryo littermates were collected and co-stained for the pro-sensory markers Sox2 or Jag1 and Myo7a, one of the earliest hair cell markers (Self et al., 1998). In all the three genotypes, we detected MYO7a-positive hair cells in the mid-basal turn and no hair cells in the apical turn. (Figures 7A-D"), indicating that hair cells do not differentiate prematurely in a base-to-apex gradient in the Lgr4 deficient embryos, However, since both heterozygous and homozygous Lgr4-LacZ embryos showed several rows of hair cells while their wild type controls had only a single one in the mid-basal turn (Figures 7B,B',B',D,D',D”), these finding suggested that the hair cells could have prematurely differentiated in a medial-to-lateral gradient in the Lgr4 deficient embryos.

\section{Lgr4 Deficient Embryos Showed Increased Proliferation in the E13 Mouse Cochlea}

To determine if the supernumerary cells observed in the Lgr4 deficient mice was associated with increased expression of "prohair cell genes" in the pro-sensory cells, as it was detected in homozygous Lgr5-eGFP cochlea, qPCR experiments were performed on E13 cochlea. In contrast to Lgr5 deficient embryos, the expression of Atoh 1 as well as that of the factors Pou $f 3$ and Nhlh1 was not increased in the Lgr4 deficient ones (Figure 8). Hence, the overproduction of hair cells did not result from the increased expression of genes required for the formation and maintenance of hair cells.

Since supernumerary cell production may be associated with an increased proliferation in pro-sensory cells, we tested the expression of Cyclin D1 (Ccnd1) in E13 cochleae. The expression of Ccnd1 increased by twofold in Lgr4 deficient embryos as compared to control littermates (Figure 8). These data were confirmed on cochlear sections obtained at the E14.5 stage by performing co-staining for SOX2-positive pro-sensory cells. In the apical turn, CCND1 was detected through the entire sensory epithelium irrespective of the genotype (Figures 9AB"). In contrast, in the mid-basal turn, CCND1 was mainly seen lateral to the pro-sensory domain in wild type cochlea,
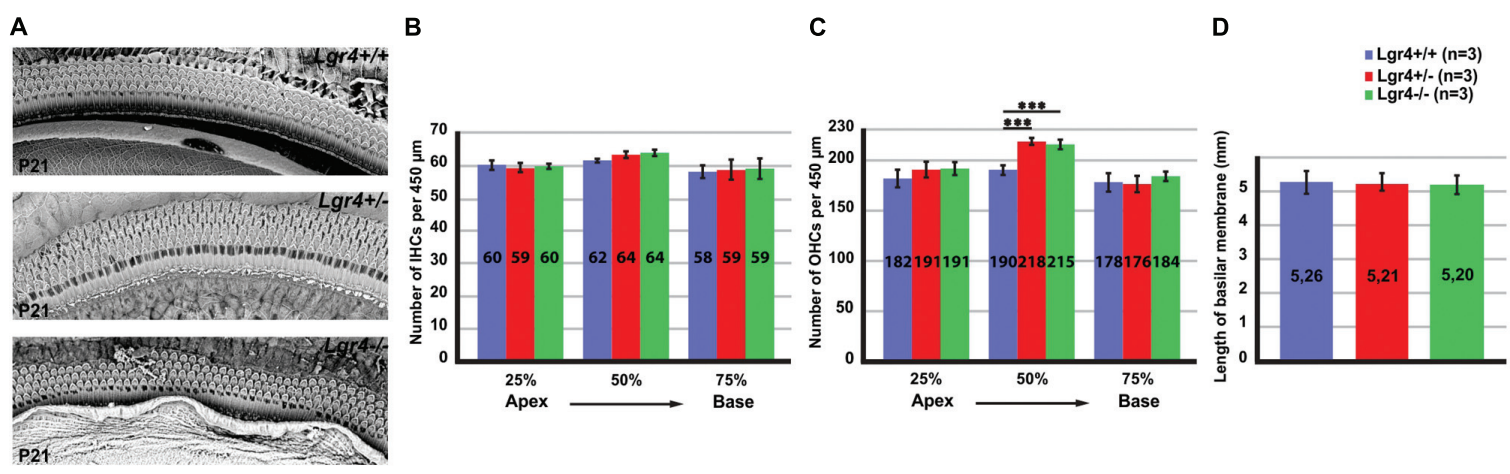

FIGURE 6 | Overproduction of hair cells in Lgr4-LacZ mice. (A) Cochlear whole mounts captured by SEM. Both heterozygous and homozygous $L$ gr4-LacZ mice showed supernumerary OHCs. (B,C) Counting $\mathrm{HCs}$ and $\mathrm{OHCs}$ along the cochlear duct showed a significant increase in the number of $\mathrm{OHCs}$ at $50 \%$ of cochleae obtained from heterozygous and homozygous $L$ gr4-LacZ mice. (D) Comparing the length of basilar membrane between the $L g r 4$ deficient mice and their wild type littermates. 

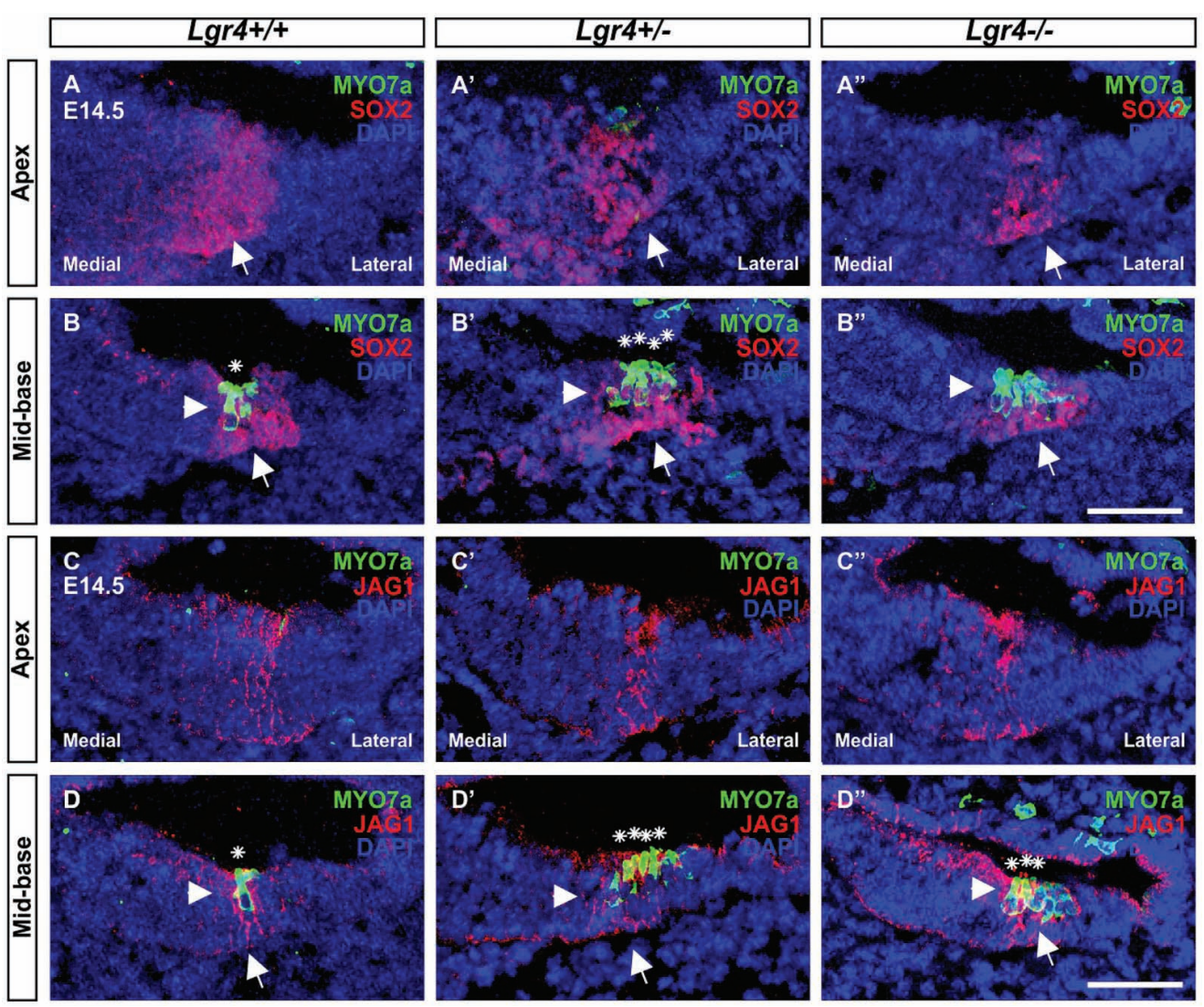

FIGURE 7 | Hair cell formation in the embryonic cochlea of $\mathbf{L g}$ r4-LacZ mice. (A-D') The cochlear cryosections obtained from Lgr4 deficient mice and their wild type counterparts were stained for a hair cell marker (MYO7a, green) and two pro-sensory cell markers (SOX2, and JAG1, both red). Developing hair cells (asterisks) were detected only in the mid-basal turns. Cell nuclei were counterstained with DAPI (blue), scale bars indicate $20 \mu \mathrm{m}$.

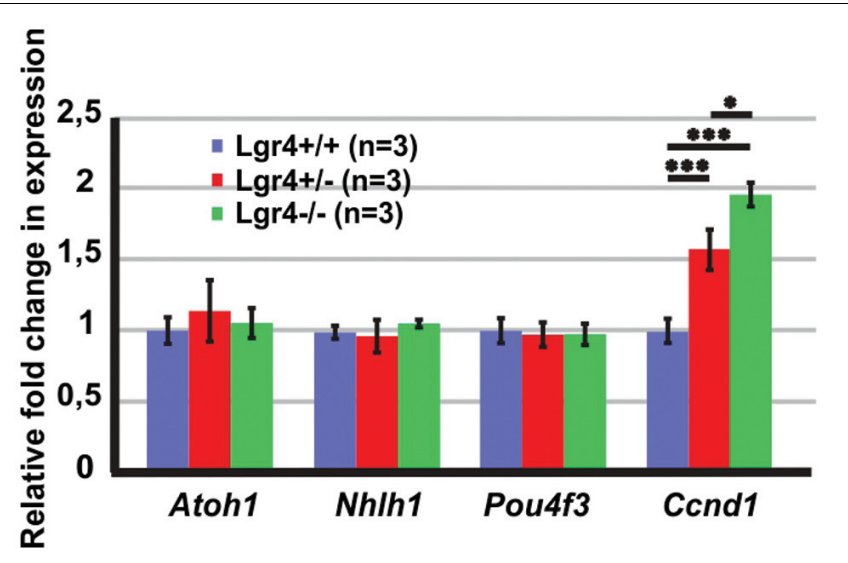

FIGURE 8 | The expression of "pro-hair cell genes" and cell cycle regulators in the E13 cochleae of Lgr4 deficient mice. The expression of Atoh1, Nhlh1, and Pou4f3 did not change, while the expression of Ccnd1 significantly increased in heterozygous and homozygous Lgr4 mice.

whereas it was also additionally detected medial and within the pro-sensory domain in heterozygous and homozygous Lgr4-LacZ embryos (Figures 9B',B”). Altogether, these results showed that the expression of CCND1 was increased in the mid-basal turn of the cochleae in Lgr4 deficient embryos. Increased proliferation of pro-sensory cells in the cochleae of Lgr4 deficient embryos was confirmed by EdU labeling of proliferating cells in vivo. Lgr4-LacZ females were injected three times with $2 \mathrm{~h}$ intervals at 13.5 days of gestation and sacrificed $24 \mathrm{~h}$ after first injection. In the E14.5 cochleae harvested from the wild type embryos, EdU-labeled cells were exclusively detected medial and lateral to the pro-sensory domain in the apical and mid-basal turns (Figures 9C,D). In heterozygous and homozygous Lgr4-LacZ embryos, EdU labeling was detected medial to the pro-sensory domain at the apical turn (Figures 9C',C”). In the mid-basal turn of the cochlea from Lgr4 deficient mice, EdU was incorporated into cells observed medial and lateral to the pro-sensory domain but also in the pro-sensory domain (Figures 9D',D”). We counted SOX2-positive cells in the mid-basal turn of the cochleae isolated from Lgr4-LacZ embryos. The number of SOX2-positive cells increased from $22.7 \pm 1.1(n=3)$ in wild type to $27.7 \pm 2.1$ $(n=3, p \leq 0.05)$ in heterozygous Lgr4-LacZ and $27 \pm 1.7(n=3$, $p \leq 0.05)$ in homozygous Lgr4-LacZ embryos. Altogether, these data suggested that the loss of LGR4 function likely results in prolonged proliferative stage in Sox2-positive cells of the prosensory domain at the mid-basal turn, leading at later fetal stages to an increased number of OHCs and supporting cells. 

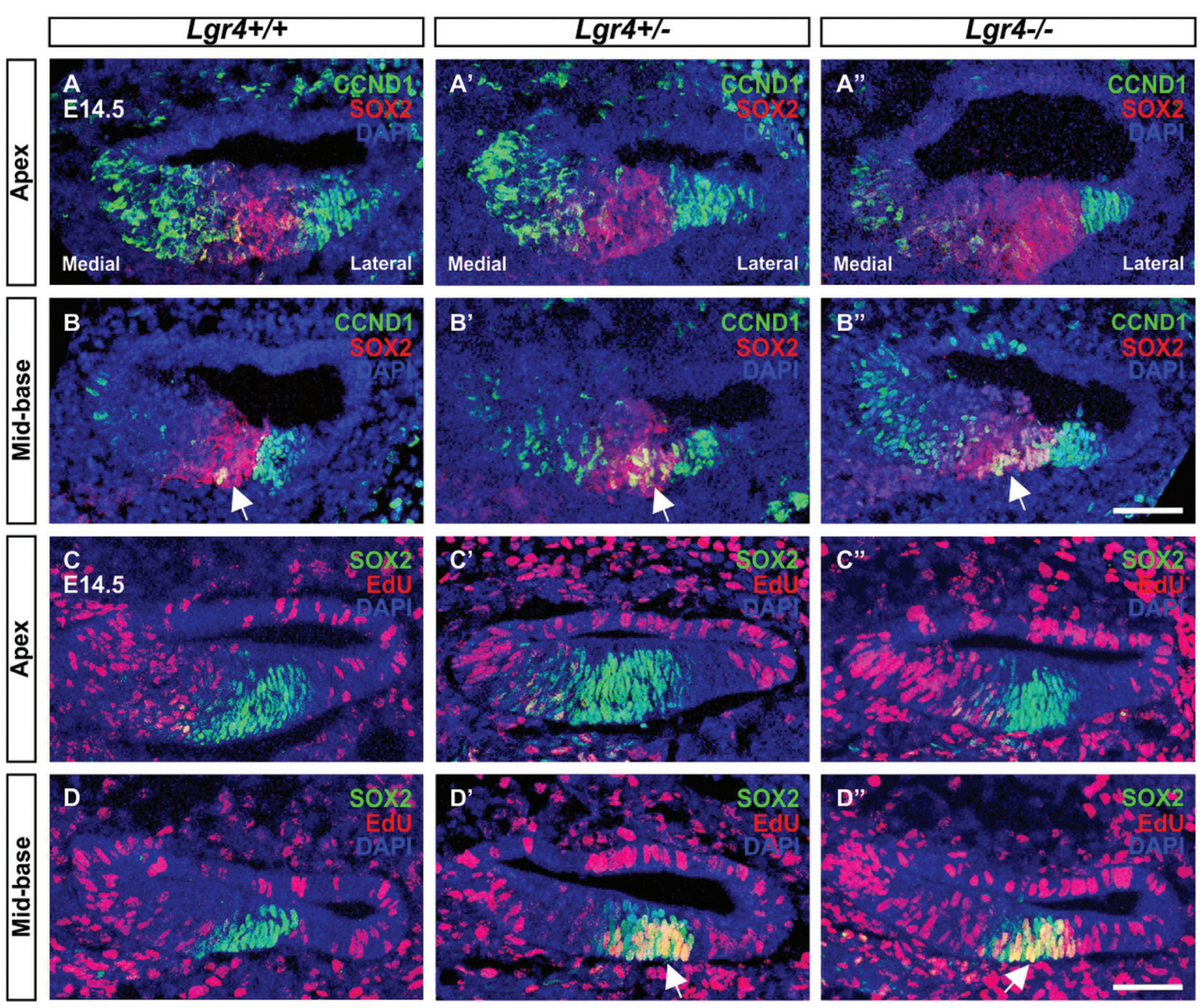

FIGURE 9 | Proliferation in the embryonic cochleae of $L g r 4$ deficient mice. (A-B' ${ }^{\prime \prime}$ In the cochleae from heterozygous and homozygous $L g r 4-L a c Z$ mice, CCND1 (green) expression increased in the mid-basal turn, where CCND1 merged with red signal of SOX2 (arrows) in the pro-sensory domain. (C-D') The proliferation marker, EdU (red), was incorporated into pro-sensory cells (arrows) positive for SOX2 (green) in the mid-basal turn of the cochlea from Lgr4 deficient mice. Cell nuclei were counterstained with DAPI (blue), scale bars indicate $20 \mu \mathrm{m}$.

\section{Lgr4 Deficient Mice Showed Changes in the Expression of Some of Wnt/ $\beta$-Catenin Target Genes}

To see if the loss of LGR4 function affects Wnt/ $\beta$-catenin signaling pathway in the developing cochlea, we tested the expression of Wnt $/ \beta$-catenin target genes and LGR proteins in the cochleae of Lgr4 deficient embryos at the age of E13 (Figure 10). Our qPCR results confirmed that the expression of Lgr4 significantly decreased according to genotype and was barely detectable in the cochleae of homozygous Lgr4-LacZ embryos (Figure 10). In contrast, Lgr5 expression (measured with the two different primer pairs), significantly increased by $2-3$ fold change in the homozygous Lgr4-LacZ embryos as compared to their wild type littermates (Figure 10) whereas Lgr6 expression was unaffected (Figure 10).

Since only one of the tested Wnt $/ \beta$-catenin target genes showed changed expression in the cochleae of Lgr4 deficient mice, we tested the expression of another $\mathrm{Wnt} / \beta$-catenin target gene. Axin 2 is a Wnt/ $\beta$-catenin target gene in the colorectal and liver tumor and in mammalian cell lines (Jho et al., 2002; Lustig et al., 2002). In the E14 mouse cochlea, Axin2 is expressed in the mesenchymal cells surrounding the cochlear duct. On the medial site, mesenchymal cells are also positive for Lgr4 (Supplementary Figure S1) and a fluorescent reporter of $\mathrm{Wnt} / \beta$-catenin activity (Jacques et al., 2012). The expression of Axin 2 decreased by a fold change of $0.4 \pm 0.1(n=3, p \leq 0.001)$ in homozygous Lgr4-LacZ embryos as compared to their wild type littermates (Figure 10). Altogether, the results suggested that Lgr4 deficiency changed the expression of some of the $\mathrm{Wnt} / \beta$-catenin target genes in the cochleae of Lgr4 deficient embryos.

\section{DISCUSSION}

In the developing cochlea, the $\mathrm{Wnt} / \beta$-catenin signaling pathway regulates two important developmental events: the proliferation of precursor cells and their differentiation into hair cells (Jacques et al., 2012, 2014; Shi et al., 2014). During these two developmental events, the activity of $\mathrm{Wnt} / \beta$-catenin signaling pathway is fine-tuned in a context dependent manner as the proliferation of precursors can be increased and prolonged by increasing Wnt/ $\beta$-catenin activity during mitotic or post-mitotic phase, while hair cell differentiation can be increased only during 


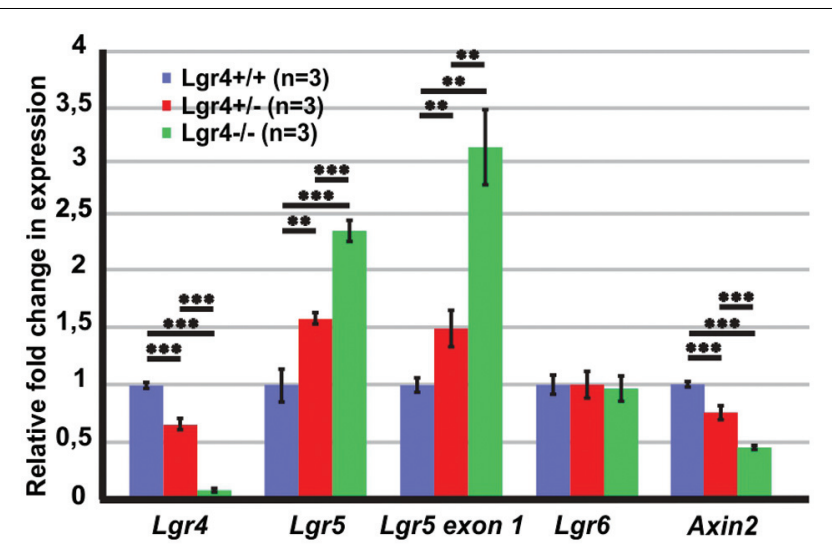

FIGURE 10 | The expression of Wnt/ $\beta$-catenin target genes in the E13 cochleae of $L$ gr4 deficient mice. The expression of $L g r 4$ significantly decreased in the cochleae of Lgr4 deficient mice, while the expression of Lgr5 and the expression from $L g r 5$ exon1 significantly increased. The expression of Lgr6 did not change, but the expression of and Axin2 significantly decreased in heterozygous and homozygous Lgr4 mice.

a short time frame between E13.5 and E16 in mice (Jacques et al., 2012). Wnt/ $\beta$-catenin signaling pathway stimulates hair cell differentiation in a base-to-apex gradient by up-regulating Atoh1 expression, which is a gene necessary for hair cell formation and over-expressing Atoh1 induces hair cell formation in the sensory and non-sensory regions of the cochlea (Bermingham et al., 1999; Zheng and Gao, 2000; Woods et al., 2004; Shi et al., 2010; Jacques et al., 2012; Shi et al., 2014; Mulvaney et al., 2015). Not much, however, is known about the molecular factors that regulate $\mathrm{Wnt} / \beta$-catenin activity in the developing cochlea.

In multiple tissues, $\mathrm{Wnt} / \beta$-catenin activity is regulated by LGR4 and LGR5 (Carmon et al., 2011; Glinka et al., 2011; Ruffner et al., 2012). LGR5 expression has already been investigated in the developing mouse cochlea (Chai et al., 2011; Shi et al., 2012), but the role of LGR4 and LGR5 in the regulation of Wnt/ $\beta$-catenin activity, proliferation, and hair cell formation had not yet been addressed.

The current study showed that the lack of $\operatorname{Lgr} 5$ function during development increases the number of hair cells and supporting cells in homozygous Lgr5-eGFP mice. This phenotype resembles effects of over-activating the $\mathrm{Wnt} / \beta$-catenin signaling pathway during hair cell differentiation, a phenotype associated with increased Atoh 1 expression and resulting in the overproduction of hair cells and supporting cells (Jacques et al., 2012). In the cochleae of homozygous Lgr5-eGFP embryos, an increased expression of Wnt/ $\beta$-catenin target genes Lgr5, Lgr6, and Atoh1 was detected. The expression of Pou $4 \mathrm{f} 3$ and Nhlh1, which are "pro-hair cell genes" positively regulated by ATOH1, was also increased in the cochleae of homozygous Lgr5-eGFP embryos (Kruger et al., 2006; Jahan et al., 2010; Klisch et al., 2011; Masuda et al., 2011; Ikeda et al., 2015).

This is compatible with the reported increased expression of Atoh1, Pou4f3, and their downstream targets in the Lgr5-positive cells, which show high proliferation and hair cell regeneration capacities when isolated from the apical turn of the cochleae of P1-P2 Lgr5-eGFP mice (Waqas et al., 2016). Previous studies have shown that the increased expression of Atoh 1 results in the overproduction of IHCs along the entire length of cochlear duct in the hypomorphic Sox 2 mice, while the increased expression of all three "pro-hair cell genes," Atoh1, Pou 4f3, and Nhlh1, increases the hair cell number in the apical turn of the cochleae of mice with conditionally deleted Neurod1 (Dabdoub et al., 2008; Jahan et al., 2010). Altogether, our data suggest that the loss of Lgr5 expression in Lgr5-eGFP embryos up-regulates Wnt/ $\beta$-catenin activity, which then increases expression of "pro-hair cell genes" leading to the overproduction of hair cells.

A similar phenotype has been observed in the intestines of Lgr5-LacZ homozygous embryos, in which the loss of LGR5 function increases $\mathrm{Wnt} / \beta$-catenin activity leading to premature Paneth cell differentiation without increased cell proliferation (Garcia et al., 2009). This result suggests that LGR5 acts as a negative regulator of the $\mathrm{Wnt} / \beta$-catenin signaling pathway in the fetal intestines (Garcia et al., 2009). The data presented in herein suggest that a similar mechanism exists in the developing mouse cochlea. Furthermore, studies using the LGR5-gain-offunction approach will further elucidate the role of LGR5 in regulating $\mathrm{Wnt} / \beta$-catenin activity and hair cell differentiation in the developing cochlea.

Recently the expression of LGR6, a close homologue of LGR5, was reported in the subset of LGR5-positive cells (Chai et al., 2011; Shi et al., 2012; Zhang et al., 2015). Here, we detected LGR4, a third member of LGR family, in a wide range of cells including the LGR5-positive cells, which suggests that all three LGR proteins are expressed in the same subset of cochlear cells.

Loss of LGR4 function also increased the number of hair cells and supporting cells in the developing cochlea, but the Lgr4 phenotype does not fully phenocopy the one from Lgr5 deficient mice. The Lgr4 deficiency increased the number of OHCs at the mid-basal turn, while the Lgr5 deficiency resulted in the overproduction of IHCs along the cochlear length and OHCs at the mid-basal turn. In the E14.5 cochleae of Lgr4 deficient mice, we observed premature hair cell differentiation in a medialto-lateral gradient in the mid-basal turn, but the expression of "pro-hair cell genes" did not increase in the Lgr4 deficient mice, which suggests that the overproduction of hair cells was induced by a different mechanism. An increased expression of Ccnd1 and the increased incorporation of EdU in the mid-basal turn of the cochleae of Lgr4 deficient mice were detected. These results implied that Lgr4 deficiency prolonged the proliferation of cells in the pro-sensory domain, which resulted in the increased number of SOX2-positive precursors that gave rise to supernumerary $\mathrm{OHCs}$ and supporting cells.

Stimulating Wnt/ $\beta$-catenin activity increases proliferation during the mitotic phase of cochlear development and results in cell cycle re-entry in the post-mitotic sensory epithelium (Jacques et al., 2012; Shi et al., 2013). Similarly to Lgr5-eGFP embryos, Wnt/ $\beta$-catenin activity could have increased in Lgr4 deficient mice leading to prolonged proliferation in the prosensory domain. However, Lgr5 was the only Wnt/ $\beta$-catenin target gene that increased the expression in the Lgr4 deficient embryos, which could result from compensation between the 
LGR family members rather than from increased $\mathrm{Wnt} / \beta$-catenin activity (Ruffner et al., 2012).

In the intestines, LGR4 is permissive to stimulate Wnt/ $\beta$-catenin activity (Mustata et al., 2011), but analyses of the expression of $\mathrm{Wnt} / \beta$-catenin target genes in the developing cochlea did not allow to conclude whether LGR4 plays the same role in the cochlea. The decrease in $\mathrm{Wnt} / \beta$-catenin activity could have been masked by mesenchymal cells that surround the cochlear duct. The mesenchymal cells could send signals that compensate for the decrease in $\mathrm{Wnt} / \beta$-catenin activity. Such a mechanism of compensation has previously been suggested to occur in the postnatal intestines of Lgr4-LacZ mice in vivo (Mustata et al., 2011). Therefore, further studies performed ex vivo, in absence of mesenchyme, would help to clarify if LGR4 is involved in the regulation of $\mathrm{Wnt} / \beta$-catenin activity in the pro-sensory precursors.

Overall, we have demonstrated that LGR4 and LGR5 are important regulators of the cell differentiation in the sensory epithelium and the proliferation of precursors. We have also revealed their complex interaction with the $\mathrm{Wnt} / \beta$-catenin signaling pathway in the developing cochlea. Further studies are necessary to fully understand the interaction between LGRs and their reported ligands from the R-spondin family. The loss of

\section{REFERENCES}

Adam, J., Myat, A., Le Roux, I., Eddison, M., Henrique, D., Ish-Horowicz, D., et al. (1998). Cell fate choices and the expression of Notch, Delta and Serrate homologues in the chick inner ear: parallels with Drosophila sense-organ development. Development 125, 4645-4654.

Atkinson, P. J., Huarcaya Najarro, E., Sayyid, Z. N., and Cheng, A. G. (2015). Sensory hair cell development and regeneration: similarities and differences. Development 142, 1561-1571. doi: 10.1242/dev.114926

Barker, N., Huch, M., Kujala, P., van de Wetering, M., Snippert, H. J., van Es, J. H., et al. (2010). Lgr5(+ve) stem cells drive self-renewal in the stomach and build long-lived gastric units in vitro. Cell Stem Cell 6, 25-36. doi: 10.1016/j.stem.2009.11.013

Barker, N., van Es, J. H., Kuipers, J., Kujala, P., van den Born, M., Cozijnsen, M., et al. (2007). Identification of stem cells in small intestine and colon by marker gene Lgr5. Nature 449, 1003-1007. doi: 10.1038/nature06196

Bermingham, N. A., Hassan, B. A., Price, S. D., Vollrath, M. A., Ben-Arie, N., Eatock, R. A., et al. (1999). Math1: an essential gene for the generation of inner ear hair cells. Science 284, 1837-1841. doi: 10.1126/science.284.5421. 1837

Bodmer, D. (2008). Protection, regeneration and replacement of hair cells in the cochlea: implications for the future treatment of sensorineural hearing loss. Swiss Med. Wkly. 138, 708-712.

Bramhall, N. F., Shi, F., Arnold, K., Hochedlinger, K., and Edge, A. S. (2014). Lgr5positive supporting cells generate new hair cells in the postnatal cochlea. Stem Cell Rep. 2, 311-322. doi: 10.1016/j.stemcr.2014.01.008

Brooker, R., Hozumi, K., and Lewis, J. (2006). Notch ligands with contrasting functions: Jagged1 and Delta1 in the mouse inner ear. Development 133, 1277-1286. doi: 10.1242/dev.02284

Carmon, K. S., Gong, X., Lin, Q., Thomas, A., and Liu, Q. (2011). R-spondins function as ligands of the orphan receptors LGR4 and LGR5 to regulate Wnt/beta-catenin signaling. Proc. Natl. Acad. Sci. U.S.A. 108, 11452-11457. doi: 10.1073/pnas. 1106083108

Carmon, K. S., Gong, X., Yi, J., Thomas, A., and Liu, Q. (2014). RSPO-LGR4 functions via IQGAP1 to potentiate Wnt signaling. Proc. Natl. Acad. Sci. U.S.A. 111, E1221-E1229. doi: 10.1073/pnas.1323106111

Chai, R., Kuo, B., Wang, T., Liaw, E. J., Xia, A., Jan, T. A., et al. (2012). Wnt signaling induces proliferation of sensory precursors in the
R-spondin 2 (Rspo2) function results in a phenotype similar to Lgr4 deficient mice (Mulvaney et al., 2013), which suggests that RSPO2 could be binding to LGR4 and not to LGR5 and that LGR4 and LGR5 may play complementary functions in cochlear development.

\section{AUTHOR CONTRIBUTIONS}

MŹ was responsible for conceiving and designing the study, $\mathrm{MZ}$ and TvO collected, assembled and analyzed the data, FH prepared cochlear cryosections and whole mounts, and carried out SEM analysis, M-IG and GV provided Lgr4-LacZ mice, MŻ, M-IG, and GV interpreted data and prepared the manuscript, WG provided administrative and financial support and approved the manuscript.

\section{SUPPLEMENTARY MATERIAL}

The Supplementary Material for this article can be found online at: http://journal.frontiersin.org/article/10.3389/fncel. 2016.00186

postnatal mouse cochlea. Proc. Natl. Acad. Sci. U.S.A. 109, 8167-8172. doi: 10.1073/pnas.1202774109

Chai, R., Xia, A., Wang, T., Jan, T. A., Hayashi, T., Bermingham-McDonogh, O., et al. (2011). Dynamic expression of Lgr5, a Wnt target gene, in the developing and mature mouse cochlea. J. Assoc. Res. Otolaryngol. 12, 455-469. doi: 10.1007/s10162-011-0267-2

Chen, M., Tian, S., Glasgow, N. G., Gibson, G., Yang, X., Shiber, C. E., et al. (2015). Lgr $5^{+}$amacrine cells possess regenerative potential in the retina of adult mice. Aging Cell 14, 635-643. doi: 10.1111/acel.12346

Chen, M., Tian, S., Yang, X., Lane, A. P., Reed, R. R., and Liu, H. (2014). Wnt-responsive Lgr5(+) globose basal cells function as multipotent olfactory epithelium progenitor cells. J. Neurosci. 34, 8268-8276. doi: 10.1523/JNEUROSCI.0240-14.2014

Chen, P., and Segil, N. (1999). p27(Kip1) links cell proliferation to morphogenesis in the developing organ of Corti. Development 126, 1581-1590.

Cotanche, D. A., and Kaiser, C. L. (2010). Hair cell fate decisions in cochlear development and regeneration. Hear. Res. 266, 18-25. doi: 10.1016/j.heares.2010.04.012

Dabdoub, A., Puligilla, C., Jones, J. M., Fritzsch, B., Cheah, K. S., Pevny, L. H., et al. (2008). Sox2 signaling in prosensory domain specification and subsequent hair cell differentiation in the developing cochlea. Proc. Natl. Acad. Sci. U.S.A. 105, 18396-18401. doi: 10.1073/pnas.0808175105

de Lau, W., Barker, N., Low, T. Y., Koo, B. K., Li, V. S., Teunissen, H., et al. (2011). Lgr5 homologues associate with Wnt receptors and mediate R-spondin signalling. Nature 476, 293-297. doi: 10.1038/nature10337

Doetzlhofer, A., Basch, M. L., Ohyama, T., Gessler, M., Groves, A. K., and Segil, N. (2009). Hey2 regulation by FGF provides a Notch-independent mechanism for maintaining pillar cell fate in the organ of Corti. Dev. Cell 16, 58-69. doi: 10.1016/j.devcel.2008.11.008

Garcia, M. I., Ghiani, M., Lefort, A., Libert, F., Strollo, S., and Vassart, G. (2009). LGR5 deficiency deregulates Wnt signaling and leads to precocious Paneth cell differentiation in the fetal intestine. Dev. Biol. 331, 58-67. doi: 10.1016/j.ydbio.2009.04.020

Gestwa, G., Wiechers, B., Zimmermann, U., Praetorius, M., Rohbock, K., Kopschall, I., et al. (1999). Differential expression of trkB.T1 and trkB.T2, truncated trkC, and p75(NGFR) in the cochlea prior to hearing function. J. Comp. Neurol. 414, 33-49. doi: 10.1002/(SICI)10969861(19991108)414:1<33::AID-CNE3>3.0.CO;2-M 
Glinka, A., Dolde, C., Kirsch, N., Huang, Y. L., Kazanskaya, O., Ingelfinger, D., et al. (2011). LGR4 and LGR5 are R-spondin receptors mediating Wnt/beta-catenin and Wnt/PCP signalling. EMBO Rep. 12, 1055-1061. doi: 10.1038/embor.2011.175

Ikeda, R., Pak, K., Chavez, E., and Ryan, A. F. (2015). Transcription factors with conserved binding sites near ATOH1 on the POU4F3 gene enhance the induction of cochlear hair cells. Mol. Neurobiol. 51, 672-684. doi: 10.1007/s12035-014-8801-y

Jacques, B. E., Montgomery, W. H., Uribe, P. M., Yatteau, A., Asuncion, J. D., Resendiz, G., et al. (2014). The role of Wnt/beta-catenin signaling in proliferation and regeneration of the developing basilar papilla and lateral line. Dev. Neurobiol. 74, 438-456. doi: 10.1002/dneu.22134

Jacques, B. E., Puligilla, C., Weichert, R. M., Ferrer-Vaquer, A., Hadjantonakis, A. K., Kelley, M. W., et al. (2012). A dual function for canonical Wnt/betacatenin signaling in the developing mammalian cochlea. Development 139, 4395-4404. doi: 10.1242/dev.080358

Jahan, I., Pan, N., Kersigo, J., and Fritzsch, B. (2010). Neurod1 suppresses hair cell differentiation in ear ganglia and regulates hair cell subtype development in the cochlea. PLoS ONE 5:e11661. doi: 10.1371/journal.pone.0011661

Jahan, I., Pan, N., Kersigo, J., and Fritzsch, B. (2015). Neurog1 can partially substitute for Atohl function in hair cell differentiation and maintenance during organ of Corti development. Development 142, 2810-2821. doi: 10.1242/dev.123091

Jaks, V., Barker, N., Kasper, M., van Es, J. H., Snippert, H. J., Clevers, H., et al. (2008). Lgr5 marks cycling, yet long-lived, hair follicle stem cells. Nat. Genet. 40, 1291-1299. doi: 10.1038/ng.239

Jan, T. A., Chai, R., Sayyid, Z. N., van Amerongen, R., Xia, A., Wang, T., et al. (2013). Tympanic border cells are Wnt-responsive and can act as progenitors for postnatal mouse cochlear cells. Development 140, 1196-1206. doi: 10.1242/dev.087528

Jansson, L., Kim, G. S., and Cheng, A. G. (2015). Making sense of Wnt signalinglinking hair cell regeneration to development. Front. Cell. Neurosci. 9:66. doi: 10.3389/fncel.2015.00066

Jeon, S. J., Fujioka, M., Kim, S. C., and Edge, A. S. (2011). Notch signaling alters sensory or neuronal cell fate specification of inner ear stem cells. J. Neurosci. 31, 8351-8358. doi: 10.1523/JNEUROSCI.6366-10.2011

Jho, E. H., Zhang, T., Domon, C., Joo, C. K., Freund, J. N., and Costantini, F. (2002). Wnt/beta-catenin/Tcf signaling induces the transcription of Axin2, a negative regulator of the signaling pathway. Mol. Cell. Biol. 22, 1172-1183. doi: 10.1128/MCB.22.4.1172-1183.2002

Kato, S., Matsubara, M., Matsuo, T., Mohri, Y., Kazama, I., Hatano, R., et al. (2006). Leucine-rich repeat-containing G protein-coupled receptor-4 (LGR4, Gpr48) is essential for renal development in mice. Nephron Exp. Nephrol. 104, e63-e75. doi: $10.1159 / 000093999$

Kawasaki, M., Porntaveetus, T., Kawasaki, K., Oommen, S., Otsuka-Tanaka, Y., Hishinuma, M., et al. (2014). R-spondins/Lgrs expression in tooth development. Dev. Dyn. 243, 844-851. doi: $10.1002 /$ dvdy.24124

Kiernan, A. E., Pelling, A. L., Leung, K. K., Tang, A. S., Bell, D. M., Tease, C., et al. (2005). Sox 2 is required for sensory organ development in the mammalian inner ear. Nature 434, 1031-1035. doi: 10.1038/nature03487

Kinzel, B., Pikiolek, M., Orsini, V., Sprunger, J., Isken, A., Zietzling, S., et al. (2014). Functional roles of Lgr4 and Lgr5 in embryonic gut, kidney and skin development in mice. Dev. Biol. 390, 181-190. doi: 10.1016/j.ydbio.2014. 03.009

Klisch, T. J., Xi, Y., Flora, A., Wang, L., Li, W., and Zoghbi, H. Y. (2011). In vivo Atoh1 targetome reveals how a proneural transcription factor regulates cerebellar development. Proc. Natl. Acad. Sci. U.S.A. 108, 3288-3293. doi: 10.1073/pnas. 1100230108

Kruger, M., Schmid, T., Kruger, S., Bober, E., and Braun, T. (2006). Functional redundancy of NSCL-1 and NeuroD during development of the petrosal and vestibulocochlear ganglia. Eur. J. Neurosci. 24, 1581-1590. doi: 10.1111/j.14609568.2006.05051.x

Laine, H., Sulg, M., Kirjavainen, A., and Pirvola, U. (2010). Cell cycle regulation in the inner ear sensory epithelia: role of cyclin D1 and cyclin-dependent kinase inhibitors. Dev. Biol. 337, 134-146. doi: 10.1016/j.ydbio.2009.10.027

Lanford, P. J., Lan, Y., Jiang, R., Lindsell, C., Weinmaster, G., Gridley, T., et al. (1999). Notch signalling pathway mediates hair cell development in mammalian cochlea. Nat. Genet. 21, 289-292. doi: 10.1038/6804
Lee, Y. S., Liu, F., and Segil, N. (2006). A morphogenetic wave of p27Kip1 transcription directs cell cycle exit during organ of Corti development. Development 133, 2817-2826. doi: 10.1242/dev.02453

Leighton, P. A., Mitchell, K. J., Goodrich, L. V., Lu, X., Pinson, K., Scherz, P., et al. (2001). Defining brain wiring patterns and mechanisms through gene trapping in mice. Nature 410, 174-179. doi: 10.1038/35065539

Liu, Z., and Zuo, J. (2008). Cell cycle regulation in hair cell development and regeneration in the mouse cochlea. Cell Cycle 7, 2129-2133. doi: $10.4161 /$ cc.7.14.6423

Lowenheim, H., Furness, D. N., Kil, J., Zinn, C., Gultig, K., Fero, M. L., et al. (1999). Gene disruption of p27(Kip1) allows cell proliferation in the postnatal and adult organ of corti. Proc. Natl. Acad. Sci. U.S.A. 96, 4084-4088. doi: 10.1073/pnas.96.7.4084

Lustig, B., Jerchow, B., Sachs, M., Weiler, S., Pietsch, T., Karsten, U., et al. (2002). Negative feedback loop of Wnt signaling through upregulation of conductin/axin2 in colorectal and liver tumors. Mol. Cell. Biol. 22, 1184-1193. doi: 10.1128/MCB.22.4.1184-1193.2002

Massague, J. (2004). G1 cell-cycle control and cancer. Nature 432, 298-306. doi: 10.1038/nature03094

Masuda, M., Dulon, D., Pak, K., Mullen, L. M., Li, Y., Erkman, L., et al. (2011). Regulation of POU4F3 gene expression in hair cells by 5' DNA in mice. Neuroscience 197, 48-64. doi: 10.1016/j.neuroscience.2011.09.033

Mendive, F., Laurent, P., Van Schoore, G., Skarnes, W., Pochet, R., and Vassart, G. (2006). Defective postnatal development of the male reproductive tract in LGR4 knockout mice. Dev. Biol. 290, 421-434. doi: 10.1016/j.ydbio.2005.11.043

Miller, T. E., Wang, J., Sukhdeo, K., Horbinski, C., Tesar, P. J., Wechsler-Reya, R. J., et al. (2014). Lgr5 Marks post-mitotic, lineage restricted cerebellar granule neurons during postnatal development. PLOS ONE 9:e114433. doi: 10.1371/journal.pone. 0114433

Montcouquiol, M., Rachel, R. A., Lanford, P. J., Copeland, N. G., Jenkins, N. A., and Kelley, M. W. (2003). Identification of Vangl2 and Scrb1 as planar polarity genes in mammals. Nature 423, 173-177. doi: 10.1038/nature01618

Morrison, A., Hodgetts, C., Gossler, A., Hrabe de Angelis, M., and Lewis, J. (1999). Expression of delta1 and serrate1 (jagged1) in the mouse inner ear. Mech. Dev. 84, 169-172. doi: 10.1016/S0925-4773(99)00066-0

Mueller, K. L., Jacques, B. E., and Kelley, M. W. (2002). Fibroblast growth factor signaling regulates pillar cell development in the organ of corti. J. Neurosci. 22, 9368-9377.

Mulvaney, J. F., Amemiya, Y., Freeman, S. D., Ladher, R. K., and Dabdoub, A. (2015). Molecular cloning and functional characterisation of chicken Atonal homologue 1: a comparison with human Atoh1. Biol. Cell 107, 41-60. doi: 10.1111/boc.201400078

Mulvaney, J. F., Yatteau, A., Sun, W. W., Jacques, B., Takubo, K., Suda, T., et al. (2013). Secreted factor R-Spondin 2 is involved in refinement of patterning of the mammalian cochlea. Dev. Dyn. 242, 179-188. doi: 10.1002/dvdy. 23908

Mustata, R. C., Van Loy, T., Lefort, A., Libert, F., Strollo, S., Vassart, G., et al. (2011). Lgr4 is required for Paneth cell differentiation and maintenance of intestinal stem cells ex vivo. EMBO Rep. 12, 558-564. doi: 10.1038/embor.2011.52

Ng, A., Tan, S., Singh, G., Rizk, P., Swathi, Y., Tan, T. Z., et al. (2014). Lgr5 marks stem/progenitor cells in ovary and tubal epithelia. Nat. Cell Biol. 16, 745-757. doi: $10.1038 /$ ncb3000

Oesterle, E. C., Chien, W. M., Campbell, S., Nellimarla, P., and Fero, M. L. (2011). p27(Kip1) is required to maintain proliferative quiescence in the adult cochlea and pituitary. Cell Cycle 10, 1237-1248. doi: 10.4161/cc.10.8.15301

Pfaffl, M. W. (2001). A new mathematical model for relative quantification in real-time RT-PCR. Nucleic Acids Res. 29:e45. doi: 10.1093/nar/29.9.e45

Plaks, V., Brenot, A., Lawson, D. A., Linnemann, J. R., Van Kappel, E. C., Wong, K. C., et al. (2013). Lgr5-expressing cells are sufficient and necessary for postnatal mammary gland organogenesis. Cell Rep. 3, 70-78. doi: 10.1016/j.celrep.2012.12.017

Qian, D., Jones, C., Rzadzinska, A., Mark, S., Zhang, X., Steel, K. P., et al. (2007). Wnt5a functions in planar cell polarity regulation in mice. Dev. Biol. 306, 121-133. doi: 10.1016/j.ydbio.2007.03.011

Ren, W., Lewandowski, B. C., Watson, J., Aihara, E., Iwatsuki, K., Bachmanov, A. A., et al. (2014). Single Lgr5- or Lgr6-expressing taste stem/progenitor cells generate taste bud cells ex vivo. Proc. Natl. Acad. Sci. U.S.A. 111, 16401-16406. doi: $10.1073 /$ pnas. 1409064111 
Ruffner, H., Sprunger, J., Charlat, O., Leighton-Davies, J., Grosshans, B., Salathe, A., et al. (2012). R-Spondin potentiates Wnt/beta-catenin signaling through orphan receptors LGR4 and LGR5. PLoS ONE 7:e40976. doi: 10.1371/journal.pone.0040976

Self, T., Mahony, M., Fleming, J., Walsh, J., Brown, S. D., and Steel, K. P. (1998). Shaker-1 mutations reveal roles for myosin VIIA in both development and function of cochlear hair cells. Development 125, 557-566.

Shi, F., Cheng, Y. F., Wang, X. L., and Edge, A. S. (2010). Beta-catenin upregulates Atoh1 expression in neural progenitor cells by interaction with an Atoh1 3' enhancer. J. Biol. Chem. 285, 392-400. doi: 10.1074/jbc.M109. 059055

Shi, F., Hu, L., and Edge, A. S. (2013). Generation of hair cells in neonatal mice by beta-catenin overexpression in Lgr5-positive cochlear progenitors. Proc. Natl. Acad. Sci. U.S.A. 110, 13851-13856. doi: 10.1073/pnas.121 9952110

Shi, F., Hu, L., Jacques, B. E., Mulvaney, J. F., Dabdoub, A., and Edge, A. S. B. (2014), beta-Catenin is required for hair-cell differentiation in the cochlea. J Neurosc. 34, 6470-6479. doi: 10.1523/JNEUROSCI.4305-13.2014

Shi, F., Kempfle, J. S., and Edge, A. S. (2012). Wnt-responsive Lgr5-expressing stem cells are hair cell progenitors in the cochlea. J. Neurosci. 32, 9639-9648. doi: 10.1523/JNEUROSCI.1064-12.2012

Snippert, H. J., Haegebarth, A., Kasper, M., Jaks, V., van Es, J. H., Barker, N., et al. (2010). Lgr6 marks stem cells in the hair follicle that generate all cell lineages of the skin. Science 327, 1385-1389. doi: 10.1126/science. 1184733

Sone, M., Oyama, K., Mohri, Y., Hayashi, R., Clevers, H., and Nishimori, K. (2013). LGR4 expressed in uterine epithelium is necessary for uterine gland development and contributes to decidualization in mice. FASEB J. 27, 49174928. doi: 10.1096/fj.13-232215

Song, S. J., Mao, X. G., Wang, C., Han, A. G., Yan, M., and Xue, X. Y. (2015). LGR5/GPR49 is implicated in motor neuron specification in nervous system. Neurosci. Lett. 584, 135-140. doi: 10.1016/j.neulet.2014.09.056

Spurr, A. R. (1969). A low-viscosity epoxy resin embedding medium for electron microscopy. J. Ultrastruct. Res. 26, 31-43. doi: 10.1016/S0022-5320(69) 90033-1

Sukhdeo, K., Koch, C. E., Miller, T. E., Zhou, H., Rivera, M., Yan, K., et al. (2014). The Lgr5 transgene is expressed specifically in glycinergic amacrine cells in the mouse retina. Exp. Eye Res. 119, 106-110. doi: 10.1016/j.exer.2013. 11.003

Takeda, N., Jain, R., Li, D. Q., Li, L., Lu, M. M., and Epstein, J. A. (2013). Lgr5 identifies progenitor cells capable of taste bud regeneration after injury. PLoS ONE 8:e66314. doi: 10.1371/journal.pone.0066314

Wang, J., Mark, S., Zhang, X., Qian, D., Yoo, S. J., Radde-Gallwitz, K., et al. (2005). Regulation of polarized extension and planar cell polarity in the cochlea by the vertebrate PCP pathway. Nat. Genet. 37, 980-985. doi: 10.1038/ng1622
Wang, Y., Dong, J., Li, D., Lai, L., Siwko, S., Li, Y., et al. (2013). Lgr4 regulates mammary gland development and stem cell activity through the pluripotency transcription factor Sox2. Stem Cells 31, 1921-1931. doi: 10.1002/stem.1438

Waqas, M., Guo, L., Zhang, S., Chen, Y., Zhang, X., Wang, L., et al. (2016). Characterization of Lgr5 + progenitor cell transcriptomes in the apical and basal turns of the mouse cochlea. Oncotarget doi: 10.18632/oncotarget.8636 [Epub ahead of print].

Woods, C., Montcouquiol, M., and Kelley, M. W. (2004). Math1 regulates development of the sensory epithelium in the mammalian cochlea. Nat. Neurosci. 7, 1310-1318. doi: 10.1038/nn1349

Xiang, M., Gan, L., Li, D., Chen, Z. Y., Zhou, L., O’Malley, B. W., et al. (1997). Essential role of POU-domain factor Brn-3c in auditory and vestibular hair cell development. Proc. Natl. Acad. Sci. U.S.A. 94, 9445-9450. doi: 10.1073/pnas.94.17.9445

Xiang, M., Gao, W. Q., Hasson, T., and Shin, J. J. (1998). Requirement for Brn-3c in maturation and survival, but not in fate determination of inner ear hair cells. Development 125, 3935-3946.

Yee, K. K., Li, Y., Redding, K. M., Iwatsuki, K., Margolskee, R. F., and Jiang, P. (2013). Lgr5-EGFP marks taste bud stem/progenitor cells in posterior tongue. Stem Cells 31, 992-1000. doi: 10.1002/stem.1338

Zak, M., Klis, S. F., and Grolman, W. (2015). The Wnt and Notch signalling pathways in the developing cochlea: formation of hair cells and induction of regenerative potential. Int. J. Dev. Neurosci. 47, 247-258. doi: 10.1016/j.ijdevneu.2015.09.008

Zhang, Y., Chen, Y., Ni, W., Guo, L., Lu, X., Liu, L., et al. (2015). Dynamic expression of Lgr6 in the developing and mature mouse cochlea. Front. Cell. Neurosci. 9:165. doi: 10.3389/fncel.2015.00165

Zheng, J. L., and Gao, W. Q. (2000). Overexpression of Math1 induces robust production of extra hair cells in postnatal rat inner ears. Nat. Neurosci. 3, 580-586. doi: 10.1038/75753

Zine, A., Aubert, A., Qiu, J., Therianos, S., Guillemot, F., Kageyama, R., et al. (2001). Hes1 and Hes5 activities are required for the normal development of the hair cells in the mammalian inner ear. J. Neurosci. 21, 4712-4720.

Conflict of Interest Statement: The authors declare that the research was conducted in the absence of any commercial or financial relationships that could be construed as a potential conflict of interest.

Copyright (c) 2016 Żak, van Oort, Hendriksen, Garcia, Vassart and Grolman. This is an open-access article distributed under the terms of the Creative Commons Attribution License (CC BY). The use, distribution or reproduction in other forums is permitted, provided the original author(s) or licensor are credited and that the original publication in this journal is cited, in accordance with accepted academic practice. No use, distribution or reproduction is permitted which does not comply with these terms. 